\title{
A large-dimensional factor analysis of the Federal Reserve's large-scale asset purchases*
}

\author{
Lasse Bork ${ }^{\dagger}$
}

April 2017

\begin{abstract}
This paper assesses the economy-wide effects of US unconventional monetary policy shocks. A precise identification of the unconventional monetary policy shocks is achieved by imposing zero and sign restrictions on a number of impulse responses from a large-dimensional dynamic factor model. In particular, an unconventional expansionary monetary policy shock is identified as a shock that increases the Federal Reserve's share of the aggregate interest rate risk and leads to an improvement in the real economy and improved credit conditions.

I find that an unconventional monetary policy shock significantly drives down the long-term interest rate spread and the credit spread, and improves both the financial market conditions and the commercial and industrial loans activity. Moreover, the impact on the real economy of this risk absorption by the Federal Reserve is significant.

The roughly $\$ 2$ trillion purchases of mortgage backed securities by the Federal Reserve Bank avoided a severe downturn according to estimates from a counterfactual analysis.
\end{abstract}

JEL codes: C32, C55, E43, E52, E58.

Keywords: unconventional monetary policy, zero lower bound, large cross-sections, dynamic factor model, factor-augmented vector autoregression (FAVAR), ExpectationMaximization algorithm

${ }^{*}$ I thank Hans Dewachter, Domenico Gianonne, Stig Vinther Møller, and Finn Olesen, as well as seminar participants at the Joint BOE, ECB, CEPR and CFM conference: Credit Dynamics and the Macroeconomy, and the Workshop on Empirical Monetary Economics in Paris for helpful comments and suggestions.

${ }^{\dagger}$ Aalborg University, Department of Business and Management, Denmark. bork@business.aau.dk 


\section{Introduction}

During 2007-2008 the Federal Reserve responded to the mounting global financial crisis with several large cuts in the federal funds rate. As a result, the federal funds target rate reached the zero lower bound (ZLB) of $0-0.25 \%$ in December 2008, down from $5.25 \%$ in August 2007, and further stimulus from conventional monetary policy was therefore exhausted. However, unconventional monetary policy initiatives was already implemented during that period to alleviate financial market dysfunctioning, and other initiatives were announced to provide further stimulus to a deteriorating economy. These initiatives are often collectively termed quantitative easing (QE) and large-scale asset purchases (LSAP) without a precise distinction between the terms ${ }^{1}$ In fact, the various expansions of the LSAP program are offten denoted by QE1, QE2, and QE3. The purpose of the US LSAP program is to improve credit conditions, and raise aggregate demand by exerting a downward pressure on longterm interest rates through massive purchases of primarily longer-term government bonds and agency MBS by the Fed. Reduced government bond yields and MBS yields should in turn reduce more risky bond yields and risk premiums, through portfolio effects and central bank signaling in general; see e.g. Joyce et al. (2012) for a discussion. Because of the LSAPs, the balance sheet of Federal Reserve has expanded to an unprecedented extent, and the effectiveness of this form of monetary policy on the real economy is still an open research question.

The size of the unconventional monetary policy initiative and the severity of most recent crisis and the is illustrated in Figure 1. The upper panel shows how the Fed's holdings of US treasury bonds, MBS and federal agency debt increased ninefold from the first QE announcement in November 28, 2008 and until 2014:Q3.2 The long-term interest rate (10year government bond yield) has generally drifted downwards, undoubtedly influenced by

\footnotetext{
${ }^{1}$ Some reserve QE to the policy targeted towards increasing the reserves of the commercial banks while LSAP is reserved to the policy targeted towards credit easing. The US and UK central bank are forerunners in LSAPs.

${ }^{2}$ Table 2 contains an overview of the QE announcements.
} 
the large cuts in the federal funds rate and the LSAPs. However, there are also periods where the long-term interest rate increases when the Fed actually expands the LSAPs or announces an expansion; see for instance the big increase in the 10-year yield after the 1,150 billion LSAP announcement on 18 March 2009, or a similar increase during the LSAP expansion from 12 December 2012 $3^{3}$ The lower panel of Figure 1 shows that the real economy has partly returned to the pre-crisis level after serious deterioration halfway into the period. Specifically, unemployment doubled the pre-crisis rate during October 2009 but is now approaching the pre-crisis rate. Moreover, industrial production has rebounded to its pre-crisis level; the stock market index is now above, while the housing market activity is still less than half of the pre-crisis level. Taking the two panels together, the conventional and unconventional monetary policy expansion seem to transmit to the long-term interest rate and real economy as expected, but while the empirical literature on the conventional monetary policy transmission mechanism is substantial, more empirical evidence is needed on the unconventional monetary policy.

Figure 1 about here

A substantial part of the empirical literature on unconventional monetary policy focuses on the impact on the 10-year government bond yield or its spread to the federal funds rate whereas the amount of empirical evidence on the real economy-wide effects is still moderate. Furthermore, most of the structural analyses are in low dimensional VARs that typically include either the 10-year spread or the Federal Reserve's holdings of securities, but not both. One might worry, however, that four or five variables in a VAR is insufficient to uncover the unconventional policy shocks, especially if the Federal Reserve holdings are excluded. Furthermore, the LSAP is targeted towards an improvement of overall financing

\footnotetext{
${ }^{3}$ A partial explanation for this observation may be that the Fed's announcement of unchanged interest rates for an 'extended period' was more credible in the latter period as shown by Swanson and Williams (2014).
} 
conditions, so a narrow focus on government bond yields with negligible credit risk and an exclusion of the more risky bond yields is probably not desirable in an assessment of the real effects of LSAP. The following observations from 2008-2009 may further highlight the challenges in estimating the effects of unconventional monetary policy.

Figure 2 shows, that during the fall of 2008, the 10-year government bond yield decreased, but the overall financing conditions continued to be depressed, as measured by a wide Baa credit spread. However, during the spring of 2009 the situation reversed with a widening of the 10-year term spread and a narrowing of the Baa credit spread. Interestingly, both periods involved QE announcements, but during the first period, with a decreasing term spread, the Fed's inventory of US treasuries (UST) and mortgage backed securities (MBS) was largely unchanged but its market share decreased, while during the second period with an increasing term spread, its market share increased, which is somewhat counter intuitive. However, the effect on the credit conditions seems to be as expected. Obviously, we need to replace eyeballing of these two periods with a model to sort out unconventional policy shocks, but the model should be able to pair innovations in the 10-year term spread with innovations in e.g. the Fed's assets, risk absorption by purchases of securities, and credit conditions in general.

Figure 2 about here

This paper contributes to a growing literature on the real effects of unconventional monetary policy by estimating US economy-wide responses to such policy shock using a largedimensional dynamic factor model. This model approach conditions the estimated policy response on a much larger information set and facilitates a structural sign identification based on more variables than in a standard VAR. Thus, in line with the discussion above, more data and new data are used to uncover the real impact of unconventional monetary policy compared to the existing literature. Furthermore, more variables are used to identify 
the policy shocks including the 10-year term spread but also real variables, credit spread, and new measures of the market impact of the Federal Reserve's LSAP. The empirical results suggests that an unconventional monetary policy shock leads to a widespread improvement in production, (un)employment, orders, housing, credit and financial conditions. The related literature on the effects of the recent unconventional monetary policy expansion can generally be organized into papers that analyze the short-term impact on long-term interest rates only, and papers that analyze the impact on the real economy over a longer horizon. Both directions are important, i.e. quantifying the policy impact on long-term interest rates is a useful first step in learning to what extent this policy is able to stimulate the real economy through the long-term interest rate.

Using event studies, Gagnon et al. (2011), Krishnamurthy and Vissing-Jorgensen (2011), and Glick and Leduc (2012) report cumulative QE1 announcement effects on the 10-year government bond yield of about -100 basis points (bps). The surprise component of the QE2 program of -18 bp. is significantly smaller in Krishnamurthy and Vissing-Jorgensen (2011), presumably because of a larger degree of financial market anticipation of the QE2 program. Note that these numbers do not measure long-run effects but rather cumulative effects over a set of one-day windows, including some announcement days with some positive effects on bond yields but with most effects being negative. Gagnon et al. (2011), D'Amico et al. (2012), and D'Amico and King (2013) find relatively smaller effects, around -40 to $-50 \mathrm{bp}$., using time series regressions. These studies, however, cannot tell us whether the reported decrease in yields leads to an improvement in the real economy.

The QE impact on the real economy has been assessed in different types of structural VARs, including small time-varying parameter VARs (TVP-VAR), Markov-switching VARs (MSVAR), large Bayesian VARs (LBVAR), and panel VARs (P-VAR). Counterfactual analyses and impulse responses are generally key ingredients in assessing the QE impact.

The large-scale BVAR of Lenza et al. (2010) and Kapetanios et al. (2012) and the dynamic factor model in this paper have their merits and demerits compared to the low-dimensional 
TVP-VAR in Baumeister and Benati (2013) or the MS-VAR in Kapetanios et al. (2012). Generally, it is computationally prohibitive to have time-varying parameters in the heavily parameterized large-scale models, so the TVP-VAR and MS-VAR have their merits if there are large structural breaks in the underlying variables or in the underlying structural relations. Therefore, I assume a reasonable stable structural relationship throughout the sample I consider. Note that Stock and Watson (2009) and Bates et al. (2013) find that factor models are rather robust to parameter instabilities. On the other hand, time-varying parameter models are usually low-dimensional and low-order due to the computational complexity, with the risk that the structural shocks cannot be uncovered (non-fundamentalness). Largescale models, however, are less vulnerable to non-fundamentalness and deficient information sets because the factor estimates and structural shocks are based on a large information set.

With 4 and 6 variables, respectively, Baumeister and Benati (2013) and Kapetanios et al. (2012) identify an unconventional monetary policy shock as a shock to the 10-year term spread but without reference to the Federal Reserve's assets. ${ }^{4}$ In contrast, Gambacorta et al. (2014), define an unconventional monetary policy shock as a shock to the central bank assets but without reference to the term spread in their P-VAR with 4 variables including the VIX index. A distinctive contributing feature of this paper is the amount of risk that is relieved from the private sector as a result of the large-scale asset purchases by the Fed. Consequently, the Fed's balance sheet and its composition of short and long bonds are related to the market composition. Another methodological feature of the paper is the data-rich identification of unconventional policy shocks, which takes advantage of the dynamic factor model's large set of potentially useful identifying variables without necessarily expanding the dimension of the state variables. Specifically, in this paper an expansionary unconventional monetary shock is identified as an expansion in the Federal Reserve's relative risk share US treasuries and MBS that has a compressing market impact

\footnotetext{
${ }^{4}$ It should be noted that Baumeister and Benati (2013) use the term "pure spread shock."
} 
on credit spreads and a positive impact on credit conditions, financial market conditions, employment, and inflation. However, measures of financial market conditions, like financial condition indices or the VIX index 5 , do not need to be included among the state variables, but are merely used to achieve a sharper identification of the policy shock.

The empirical results of this paper generally support the modest empirical evidence on the real effects of unconventional monetary policy, but are much broader in the coverage of the US economy. Baumeister and Benati (2013) perform a counterfactual analysis of the real effects of a 10-year term spread that is 60 bps higher throughout 2009. The higher term spread would have resulted lowered inflation by 1 percentage point, lowered real GDP by $0.9 \%$, and increased unemployment rate by 0.75 percentage point. Kapetanios et al. (2012) consider a TVP-VAR, MS-VAR and a LBVAR for the UK and use an identification approach similar to Baumeister and Benati (2013). Their counterfactual analysis with a 100 bp higher term spread is significantly model dependent, whereby the TVP-VAR and MS-VAR deliver more than a 5 percentage point decrease in GDP and more than a 3 percentage point decrease in inflation, while the LB-VAR results in 1 and 0.28 percentage point, respectively. Gambacorta et al. (2014) consider a narrow sample from 2008:012011:06, but their panel VAR of eight countries should add up for the loss of power due to the small sample, according to the authors. Across the eight countries, the responses of prices and output to balance sheet shocks are generally similar and significantly positive. $\mathrm{Wu}$ and Xia (2014) replace the federal funds rate in a large dynamic factor model with a shadow rate, which can be negative when the federal funds rate is stuck at the ZLB. The shadow rate shock is identified recursively and the impulse responses are comparable to the evidence on conventional policy shocks, although a price puzzle seems to exist in Wu and Xia's (2014) analysis.

The remainder of this paper is organized as follows. The structural dynamic factor model (SDFM) is presented in Section 2, identification issues and the estimation method are

\footnotetext{
${ }^{5}$ Chicago Board Options Exchange Market Volatility Index
} 
presented in Section 3. Section 4 describes the data, Section 5 details the empirical results, and Section 6 concludes.

\section{Model framework: A dynamic factor model}

Since the first generation of dynamic factor models (DFM) of Geweke (1977) and Sargent and Sims (1977), a considerable amount of research has been devoted to the econometric theory and empirical analysis of approximate ${ }^{6}$ factor models of high dimension, notably the generalized dynamic factor model by Forni et al. (2000, 2004, 2005) and the static representation of the dynamic factor model by Stock and Watson $(2002 a b)$. The premise of the dynamic factor model is that a set of $N$ observed time series variables obey a factor structure, such that the comovement of the $N$ variables can be described in terms of $q<<N$ common dynamic latent factors, $f$, while the remaining unexplained portion of a variable resides in an idiosyncratic component $\xi$ specific to each variable. As in Forni et al. (2005), the time $t$ observed variables in $X_{t}$ are linear combinations of the current and lagged values of the dynamic factors:

$$
X_{t}=\lambda^{\top}(L) f_{t}+\xi_{t},
$$

where $\lambda(L)=\lambda_{0}+\lambda_{1} L+\ldots+\lambda_{s} L^{s}$ is a $q \times N$ polynomial matrix of factor loadings in the lag-operator $L$, and where the common factors dynamics are given by a $V A R(h)$ process

$$
f_{t}=\phi(L) f_{t-1}+u_{t}
$$

with $* * * *$ WRONG7: $\phi(L)=\phi_{1} L+\ldots+\phi_{h} L^{h}$ being a $q \times q$ polynomial matrix of autore-

\footnotetext{
${ }^{6}$ In the first generation exact factor models like Ross (1976), Geweke (1977), Sargent and Sims (1977), and Geweke and Singleton (1981), the idiosyncratic components are orthogonal. However, the approximate factor models allow for some "local" correlation among the idiosyncratic components.

${ }^{7}$ Should probably be

$$
I+\phi_{1} L+\ldots+\phi_{h-1} L^{h-1}
$$
}

or better

$$
\phi_{1}+\phi_{2} L+\ldots+\phi_{h} L^{-1}
$$


gressive coefficients. The dynamic factor model can be written in a state space form

$$
\begin{aligned}
& X_{t}=\Lambda F_{t}+\xi_{t} \\
& F_{t}=\Phi(L) F_{t-1}+U_{t}
\end{aligned}
$$

where the dimension of $F_{t}=\left[f_{t}^{\top}, \ldots, f_{t-s}^{\top}\right]$ is $r=q(s+1)$ and $\Lambda=\left[\lambda_{0}, \ldots, \lambda_{s}\right]$ is $N \times r$. Moreover, $\Phi(L)$ is of order $p=\max (1, h-s)$ and therefore depends on the response heterogeneity of the panel $(s)$ relative to $h$; see Bai and $\mathrm{Ng}(2007)$ or Bai and Wang (2014b) for more details. Furthermore, $U_{t}=\left[u_{t}^{\top}, 0_{q s \times 1}^{\top}\right]^{\top}$. To fix ideas, I assume that $\xi_{t} \sim N(0, R)$ with $R$ being a diagonal matrix corresponding to an exact factor model, but this assumption is later relaxed. Throughout the paper, I assume $u_{t} \sim N(0, W)$. The VAR component in (1) is assumed stationary and hence invertible. This implies that a vector moving average representation (VMA) of the model exists

$$
X_{t}=C(L) u_{t}+\xi_{t}
$$

where $C(L)=\Lambda\left[I-\Phi(L)^{-1}\right] V$, and $V$ is a selection matrix such that $U_{t}=V u_{t}$.

The unknowns in this Gaussian state space model are the parameters in $\Theta=\{\Lambda, R, \Phi(L), Q\}$ and the latent dynamic factors $f_{t}$. However, the state space system in (1) is not econometrically identified as it is possible to form observationally equivalent models by arbitrary rotations of the latent factors, $F_{t}$, and the loadings $\Lambda$. Consequently, it is not possible to estimate a unique set of parameters $\hat{\Theta}$ with the data unless identifying restrictions are imposed on $\Theta$. In addition, further restrictions are needed to identify the structural DFM from the reduced form DFM in (1). Section 2.1 discusses the econometric identification, Section 2.2 covers structural identification, and Section 3 describes maximum likelihood estimation.

or

$$
\phi(L) f_{t}=u_{t}
$$




\section{$2.1 \quad$ Econometric identification}

The dynamic factor model above is estimated with a fully parametric maximum likelihood method, the iterative Expectation Maximization (EM) algorithm, and this method is discussed shortly. A number of parametric identification approaches have been proposed in the literature. The predominant starting point is uncorrelated factors, which implies that the identification of the sources of variation in the panel $X$ is then a matter of imposing an identifying structure on the loading matrix; in particular, a hierarchical structure that embodies the separation of the contribution of the factors to the variation in $X$. Important contributions describing this approach include the seminal paper by Geweke and Singleton (1981) (proposition I), Geweke and Zhou (1996), and Aguilar and West (2000). Alternatively, the assumption about uncorrelated factors can be relaxed by allowing for correlated factors. However, less restricted factor dynamics would have to be compensated for by a more restrictive simple structure on the loading matrix, in order to be able to separate the sources of variation; see Geweke and Singleton (1981) (proposition II) and recent work by Bai and Wang (2014b) and Bai and Wang (2014a).

In this paper, the identification scheme with correlated factors is preferred as most economic factors would be correlated, in contrast to the orthogonal factors from the popular principal components methods. Essentially, the identification approach for correlated factors constrains a small $q \times q$ subset of the large $N \times q(s+1)$ loading matrix to be an identity matrix. The variance-covariance matrix of the reduced form VAR residuals, $W$, is left completely unrestricted, which is ideal for the structural analysis.

Although the dynamic factors are identified by either of the above identification schemes, they are still unobserved and latent in nature. But macroeconomic data are generally prone to measurement errors, so a latent dynamic factor representation is a useful device to distinguish the underlying trend of inflation or employment, for example, from measurement errors 8 Yet, in some cases it makes more sense to analyze structural policy shocks to a

\footnotetext{
${ }_{8}^{8}$ Sargent $(1989)$ shows how the existence of measurement error leads to a dynamic factor index model.
} 
real and observed series rather than a factor representation of a series; for instance, the perfectly measured federal funds rate. Consequently, I follow Bernanke et al. (2005) and augment the factors $F_{t}$ with the perfectly measured federal funds rate, so that the factors are estimated jointly with this important variable.

\subsection{Structural identification}

The VMA representation of the DFM in (2) is not unique since the impulse responses are not yet structurally identified. A popular approach to the structural identification is the recursive identification by the computationally convenient Cholesky decomposition of Cov $\left(u_{t}\right)$, which would effectively impose $q(1+1) / 2$ exactly identifying zero restrictions. Bernanke et al. (2005) impose a recursive identification scheme directly on the VAR impact matrix in their factor-augmented VAR (FAVAR) while Forni and Gambetti (2010) impose the recursive identification scheme on the impulse responses, that is, on $C(L)$. The Cholesky decomposition, however, imposes a causal chain on the shocks, and the imposition of a strict number of zero restrictions may lack economic motivation.

As an alternative to the exactly identifying zero restrictions, Faust (1998), Uhlig (2005), and Canova and Nicolo (2002) propose to set identify SVAR models by imposing sign restrictions on the impulse responses. Uhlig, for instance, proposes to identify monetary policy shocks by imposing only weak sign restrictions on the impulse responses over a given

period. In particular, he defines a contractionary monetary policy shock as one that leads to a negative price response, a positive response of nonborrowed reserves, and a non-negative response of the federal funds rate for a certain period following the shock. The idea is to generate a large number of alternative models using orthogonal rotations and to keep only the draws that generate impulse responses that are consistent with the economically motivated sign restrictions. This means that a unique model is not identified; instead, a set of admissible structural models that all are consistent with the sign restrictions is identified. Thus, a hypothesis can be ruled out if none of the draws satisfies the restrictions, or one can 
question whether the range of admissible impulse responses is too wide. More confidence in the identification of the structural shock will emerge if the shock satisfies a number of sign restrictions, if it seems distinctive from other competing shocks, and if the range of impulse responses is narrow and significantly different from zero; see Fry and Pagan (2011) and Kilian (2013) for a thorough discussion.

The starting point for generating candidate models is a base set of uncorrelated structural shocks and this basis is then rotated into a new model with a new set of uncorrelated shocks and impulse responses. The Cholesky decomposition of $\operatorname{Cov}\left(u_{t}\right)=A_{0}^{-1}\left(A_{0}^{-1}\right)^{\top}$ is a simple way to have uncorrelated structural shocks given by $\varepsilon_{t}=A_{0} u_{t}$. Rotating $\varepsilon_{t}$ by the orthogonal matrix $Q$ gives a new set of uncorrelated shocks, $\tilde{\varepsilon}_{t}=Q^{\top} A_{0} u_{t}$, where $Q^{\top} A_{0}$ in general will be nonrecursive. The new impulse responses are then given by $\tilde{B}(L)=$ $B(L) Q=C(L) A_{0}^{-1} Q=\Lambda\left[I-\Phi(L)^{-1}\right] V A_{0}^{-1} Q$, which can be evaluated against the imposed restrictions.

Sometimes the impulse responses are required to satisfy a combination of zero and sign restrictions, for instance in separating monetary policy shocks from aggregate demand shocks. This could be accomplished by requiring that real variables do not respond within the period to a monetary policy shock, i.e. a zero restriction. However, the combination of zero restrictions with sign restrictions has been quite difficult to implement in practice, although a penalty function approach has been proposed by Mountford and Uhlig (2009). Recently, Arias et al. (2014) propose a fast algorithm that draws $Q$ from the correct distribution of sign restrictions conditional on the zero restrictions $9^{9}$ They show that the existing algorithms implicitly introduce sign restrictions in addition to the ones specified in the identification, which generate biased impulse response functions and artificially narrow confidence intervals.

The structural identification in this paper relies on a combination of zero and sign restrictions and builds on the algorithm of Arias et al. (2014). The appendix contains a summary

\footnotetext{
${ }^{9}$ See also Binning (2013) for a related paper.
} 
of the algorithm. In the light of the LSAP program, I define and focus on an unconventional monetary policy shock but also define an expansionary conventional monetary policy shock, an aggregate demand shock, and aggregate supply shock; the latter three shocks are helpful in addressing the "multiple shock problem" discussed in Fry and Pagan (2011). Specifically, I define an unconventional monetary policy shock (uMP) as one that (i) increases the Federal Reserve's interest rate risk of the UST and MBS holdings relative to the same market risk (duration), (ii) decreases the credit spread, (iii) improves the financial market conditions, and (iv) increases inflation and output (employment, industrial production). An expansionary conventional monetary policy shock (cMP) is defined as a decrease in the federal funds rate and an increase in inflation and output. To further distinguish the unconventional policy shock from the conventional, zero restrictions are imposed so that the federal funds rate does not respond initially to an unconventional policy shock. A positive aggregate supply shock (AS) is defined as a shock that leads to a decrease in inflation and an increase in output; a similar definition is seen in Baumeister and Benati (2013). A positive aggregate demand shock (AD) moves inflation, output, and the interest rate in the same direction, which can be distinguished from a conventional expansionary monetary policy shock that would have the opposite sign on the interest rate ${ }^{10}$ A summary of the shocks for my baseline model is given in Table 3, where $(+)$ or $(-)$ indicate the required sign, (*) means unrestricted, and (0) indicates an initial zero restriction. In addition, one may define the sign restriction to hold in each of $J_{i}$ periods or cumulatively over the $J_{i}$ periods, while the zero restrictions may be required to hold for one or more periods.

Table 1 about here

\footnotetext{
${ }^{10}$ To further separate policy shocks from non-policy shocks, one could impose zero restrictions on the initial response of inflation and output to policy shocks. The results are not found to be sensitive to imposing these zero restrictions.
} 


\section{Estimation}

The linear Gaussian state space model in (1) with its latent factors $f_{t}$ is well represented in a Kalman filter setting. Building on the seminal work by Dempster et al. (1977), Shumway and Stoffer (1982), and Watson and Engle (1983) introduce the EM algorithm to estimate the parameters in state space models as in the model above. Doz et al. (2012) also use the EM algorithm in their study of the asymptotic properties of QML estimation for large approximative factor models and show that this method is robust to misspecification that arises from weak cross-sectional and serial correlation of the idiosyncratic errors. Finally,

Jungbacker and Koopman (2014) show how one could speed up the maximum likelihood estimation of a large DFM.

Essentially, the EM algorithm is an iterative maximum likelihood method that switches between an Expectation step and a Maximization step. The maximization step results in the following closed form estimators at iteration $j$

$$
\begin{aligned}
\Lambda^{(j)} & =D C^{-1} \\
R^{(j)} & =\frac{1}{T} \sum_{t=1}^{T}\left(X_{t}-\Lambda^{(j-1)} \hat{F}_{t \mid T}\right)\left(X_{t}-\Lambda^{(j-1)} \hat{F}_{t \mid T}\right)^{\top}+\Lambda^{(j-1)} \hat{P}_{t \mid T}\left[\Lambda^{(j-1)}\right]^{\top} \\
\Phi^{(j)} & =B A^{-1} \\
W^{(j)} & =\frac{1}{T}\left[C-B A^{-1} B^{\top}\right]
\end{aligned}
$$

where the following moments are available from the Kalman smoother (indicated by subscript $t \mid T)$ :

$$
\begin{array}{ll}
A=\sum_{t=1}^{T}\left(\hat{F}_{t-1 \mid T} \hat{F}_{t-1 \mid T}^{\top}+\hat{P}_{t-1 \mid T}\right) & B=\sum_{t=1}^{T}\left(\hat{F}_{t \mid T} \hat{F}_{t-1 \mid T}^{\top}+\hat{P}_{\{t, t-1\} \mid T}\right) \\
C=\sum_{t=1}^{T}\left(\hat{F}_{t \mid T} \hat{F}_{t \mid T}^{\top}+\hat{P}_{t \mid T}\right) & D=\sum_{t=1}^{T} X_{t} \hat{F}_{t \mid T}^{\top}
\end{array}
$$

and where $\hat{F}_{t \mid T}=E\left[F_{t} \mid \mathbb{X}_{T}\right], \hat{P}_{t \mid T}=\operatorname{var}\left(F_{t} \mid \mathbb{X}_{T}\right), \hat{P}_{\{t, t-1\} \mid T}=\operatorname{Cov}\left(F_{t}, F_{t-1} \mid \mathbb{X}_{T}\right)$ and $X_{T}=\left\{X_{1}, . ., X_{T}\right\}$ denotes the information set. The estimated parameters from iteration 
$j$ in $\Theta^{(j)}=\left\{\Lambda^{(j)}, R^{(j)}, \Phi^{(j)}, W^{(j)}\right\}$ in addition to certain initial values, can then be used in the expectation step to compute a new set of moments from the Kalman smoother. Subsequently, the estimated moments are supplied to the maximization step above from which $\Theta^{(j+1)}$ can be calculated, and the procedure continues until convergence of the likelihood. The econometrically identifying restrictions discussed in Section 2.1 are not yet imposed on the estimated loadings in $\Lambda^{(j)}$ because these are still fully unrestricted. However, Bork et al. (2009) derive the loading estimator subject to a set of linear loading restrictions in the form $H_{\Lambda} \operatorname{vec} \Lambda=\kappa_{\Lambda}$ that takes this form

$$
\begin{aligned}
\operatorname{vec}\left(\Lambda^{(j-1) *}\right)= & \operatorname{vec}\left(\Lambda^{(j)}\right) \\
& +\left(C^{-1} \otimes R^{(j-1)}\right) H_{\Lambda}^{\top}\left[H_{\Lambda}\left(C^{-1} \otimes R^{(j-1)}\right) H_{\Lambda}^{\top}\right]^{-1} \times \\
& +\left\{\kappa_{\Lambda}-H_{\Lambda} \operatorname{vec}\left(\Lambda^{(j)}\right)\right\}
\end{aligned}
$$

The Kalman filter and the EM algorithm can also handle missing observations among the observed variables. A specific form of missing observations can be seen in unbalanced panels in which some of the included time series may have their first observation later in the sample compared to other series with a full sample. In this paper, I want to condition the policy response on measures of financial market conditions, but such measures typically have their first observation in the 1970 s or later. ${ }^{11}$ Nevertheless, it is possible to filter the series with missing observations based on their estimated loadings on the dynamic factors. It turns out that the required modification amounts to slightly changed estimators of (3), (4), and (8) only; see Shumway and Stoffer (1982) and Shumway (2000) for more details. In particular, I define a time-varying indicator matrix, $I_{t}$ that has ones along the diagonal unless the $i$ th variable has a missing observation at time $t$, in which case element $(i, i)$ is zero. Then (3)

\footnotetext{
${ }^{11}$ To mention a few, the VIX option implied volatility series starts in 1986:06, and the Chicago NFCI condition index starts in 1973:01. For the other series, see the last 7 series in Appendix A
} 
and (4) becomes

$$
\begin{aligned}
\Lambda^{(j)}= & {\left[\sum_{t=1}^{T} \tilde{X}_{t} \hat{F}_{t \mid T}^{\top}+\left(I-\mathcal{I}_{t}\right) \tilde{\Lambda}_{t}^{(j-1)} A\right] C^{-1} } \\
R^{(j)}= & \frac{1}{T} \sum_{t=1}^{T}\left\{\left(\tilde{X}_{t}-\tilde{\Lambda}_{t}^{(j-1)} \hat{F}_{t \mid T}\right)\left(\tilde{X}_{t}-\tilde{\Lambda}_{t}^{(j-1)} \hat{F}_{t \mid T}\right)^{\top}\right. \\
& \left.+\tilde{\Lambda}_{t}^{(j-1)} \hat{P}_{t \mid T}\left[\tilde{\Lambda}_{t}^{(j-1)}\right]^{\top}+\left(I-\mathcal{I}_{t}\right) R^{(j-1)}\right\}
\end{aligned}
$$

where $\tilde{X}_{t}=I_{t} X_{t}$ is the time $t$ observed variables that may have zero elements in case of missing observations and similarly for the rows in $\tilde{\Lambda}_{t}^{(j-1)}=I_{t} \Lambda^{(j-1)}$. Equation (8) should be based on $\Lambda^{(j)}$ in $(3)$ and $R^{(j)}$ in $(4)$.

*** Add ref. to Banbura.

\section{Data}

In general, the dataset is an updated and extended version of the balanced panel used by Bernanke et al. (2005). Updating their data to 2014:09 recovers $93 \%$ of their series as some series have been discontinued. Fourteen new variables are added to the extended panel, such that a total of 126 variables are included that cover 1959:01 to 2014:09. The new series are primarily measures of the Federal Reserve assets and its market share of UST and MBS. Important financial market condition measures are added to the panel in order to closely approximate the information that the Federal Reserve Board bases its decision upon. In particular, the National Financial Condition Index (NFCI) of the Federal Reserve Bank of Chicago is included, as well as the Kansas City Financial Stress Index, the VIX index, the TED spread, and the MOVE index, to mention a few of these series. These series, however, have a shorter sample so that the panel becomes unbalanced, but the EM algorithm can handle this as shown above. All the series are seen in Appendix A and the 
series in general represent the following categories of macroeconomic and financial time series: output and income; (un)employment, hours and earnings; housing; consumption, orders and inventories; money and credit; bond and exchange rates; consumer, producer prices, and commodity prices; stock prices; the Federal Reserve's assets, and financial condition measures.

The components of the Federal Reserve's balance sheet are in general not available online for the complete sample and have thus been obtained from various issues of the digitized Federal Reserve Bulletin archived at the Federal Reserve Archive (FRASER). As a result, the Federal Reserve's total assets and its holdings of UST and MBS have been obtained partly from the Federal Reserve Bulletins and the H.4.1 releases at www.federalreserve.gov. The total Federal Reserve Bank assets together with a measures of the Fed's market share of UST and MBS interest rate risk are shown in Figure 2, with a recent decomposition of the assets into main components is shown in Figure 3. ** Work in progress: Perhaps add more text about the calculation of the Federal Reserve's relative risk share; see the text under figure $* *$

Figure 3 about here

\section{$5 \quad$ Empirical results}

In the end, I estimate a baseline model with 6 dynamic factors from the panel of 126 time series and show that an expansionary unconventional monetary policy shock leads to a significant increase in industrial production, employment, inflation, housing starts, and capacity utilization, in addition to a decrease in the 10-year yield spread, the credit spread, and the market volatility. The background for these results are organized as follows. I first comment on the factor estimates and provide a brief discussion of the estimation procedure. Economy-wide impulse responses following an unconventional monetary policy shock are 
then presented with a counterfactual analysis. Finally, I present some robustness results and close this section with a discussion.

\subsection{Dynamic factor estimates and the estimation procedure}

The baseline model contains 6 dynamic factors that are related to inflation, unemployment, employment, the changes in the Federal Reserve's relative risk share, the federal funds rate and the credit spread. The federal funds rate and the Federal Reserve's risk share are measured without error in (1). I choose to measure these two policy variables without error so that any estimated policy shock belongs to a precisely measured policy variable and therefore is uncontaminated by any factor approximation error of the policy variable. The number of factors are determined by the information criterion by Hallin and Liska (2007), and their $I C_{1 ; n}^{T}$ and $I C_{2 ; n}^{T}$ point toward $4-6$ factors. The information criterion has guide me in the number of factors but subsequently I have to decide on the $q=6$ observed variables in $X$ that should carry the identifying loading restrictions discussed in Section 2.1. A preliminary principal component analysis tell me what kind of variables will predominantly load on the first principal component, the second, etc., and this insight is used to determine the subset of $X$ that have a simple loading structure. If the final factor estimate turns out to be quite different from the characteristics of the restricted variable, then one may consider adjusting the identifying restrictions. However, it is my experience that the dominant factors are the ones listed in the beginning of this section. The number of lags in the VAR is $p=10$, and this has been determined to be the most parsimonious model consistent with absence of residual autocorrelation, which is important for the structural analysis.

In the EM algorithm, I impose the exactly identifying restrictions on the inferred dominant factors and initially filter the factors with very weak priors on the initial parameter estimates. In particular, the loading matrix is filled with zeros except for the exactly identifying unit restrictions, and a few initial iterations with this simple loading matrix are undertaken 
in order to filter the factors. After the initial iterations, the complete loading matrix is estimated and the algorithm continues until the likelihood value and the parameter estimates have converged.

Figure 4 shows the estimated factors together with the single most correlated observed variable in the panel. The first factor captures the underlying inflation and the second factor is related to unemployment, whereby the latter has a 0.94 correlation with unemployment duration measures and a 0.85 correlation with the overall unemployment rate. The third factor is mainly related to employment growth but is highly correlated with measures of economic activity such as industrial production series $(\sim 0.75)$, capacity utilization (0.5), and PMI (0.82). The fourth factor is the Fed's relative risk share of UST and MBS, the fifth is the federal funds rate, and the sixth factor is related to credit spreads and term spreads in general.

Figure 4 about here

\subsection{Impulse response analysis}

Consider now the impulse responses for the baseline model. Based on the sign restrictions in Section 2.2, the results of the estimated economy-wide responses of an expansionary unconventional monetary policy shock are shown in Figure 5. In particular, an unconventional shock significantly drives down the long interest rate spread (10yr - FF spread); the credit spread (Baa less 10yr); and increases the commercial and industrial loans (C\&I loans). Thus, the credit conditions seem to be improved. Industrial production, capacity utilization, inflation (CPI-U), and employment respond in a significantly positive way, while unemployment is significantly reduced. Note that I remain agnostic about unemployment as no sign restrictions are imposed. Financial market conditions seem to be improved as measured by a lowered MOVE volatility index. All impulse responses are normalized to show the response of a $1 \%$ innovation in the market share. For the included 25 variables, 
the responses are in general plausible and significant, so the LSAP program seems to have the desired impact on both credit conditions and the real economy. It should be noted that the positive response of the Federal Reserve's assets (measured in annual growth) is replaced by a negative response after one year, but the dynamics of this variable is indeed very special as seen in Figure 3. For other model specifications the longer-term response of this variable turns out to be insignificantly different from zero. The illustrated responses are robust to other model specifications and the choice of lags in the VAR as detailed in the section below with robustness analyses.

Figure 5 about here

*** Work in progress: Identification by sign restrictions combined with narratives on event study and QE.

\subsection{Counterfactual analysis}

What would have happened if the Federal Reserve did not embark on LSAPs? Would the unemployment rate be much higher and would we see a worsening of the deflationary tendencies? Were the credit spread even higher? These are all important questions that we wish we could answer, in particular in evaluating the observed policy actions. In an attempt to provide some answers to these important questions, I perform a counterfactual analysis on the basis of my estimated baseline model. Specifically, I consider the hypothetical case of no Federal Reserve Bank purchases of MBS and analyze the counterfactual outcome in terms of (un)employment, inflation, output, credit spreads, and financial conditions. The key to this analysis is the elimination of the all the purchases of MBS resulting in a counterfactual lower market share. This approach focuses on the real effect of the LSAPs of MBS and is an alternative to the counterfactual analysis in Baumeister and Benati (2013) and Kapetanios et al. (2012) where 60 to 100 bps are added to the term spread. 
Counterfactual analyses in SVARs are seen in a number of papers, including Bernanke, Gertler, and Watson (1997) and Herrara \& Hamilton (2004). Imagine that we want to study the result of a counterfactual development in the $j$ th variable in $X_{t}$ during the period $t$ to $t^{*}$, that is, to consider a particular counterfactual sequence $\left\{X_{j, \tau}^{*}\right\}_{\tau=t}^{t^{*}}$, where $X_{j, \tau}^{*}$ is different from the observed $X_{j, \tau}$. This amount to choosing the structural shocks $\left\{\varepsilon_{j, \tau}^{*}\right\}_{\tau=t}^{t^{*}}$ such that $X_{j, \tau}^{*}$ is achieved, while the remaining shocks are unchanged.

The starting point for the counterfactual analysis is the historical decomposition of $X_{t}$ in terms of the structural shocks. Because the market share has a simple loading structure (a single unit loading) it suffices to briefly describe the theory in terms of the moving average representation and the historical decomposition of the factors only ${ }^{12}$, The structural moving average representation $F_{t}=\sum_{i=1}^{\infty} \Psi_{j} \varepsilon_{t-j}$ follows from (1) where the recursion for $\Psi_{j}$ is provided in e.g. Luetkepohl (2011) or Lütkepohl (2005), and from this the historical decomposition can be derived as

$$
F_{t}=\sum_{i=0}^{t-1} \Psi_{i} \varepsilon_{t-i}+\Phi_{1}^{(t)} F_{0}+\ldots+\Phi_{p}^{(t)} F_{-p+1}
$$

with $\left[\Phi_{1}^{(t)}, \ldots, \Phi_{p}^{(t)}\right]$ defined as the first $r$ rows of the corresponding $r p \times r p$ companion matrix raised to the power of $t$. In case we seek a particular value of the $F_{j, \tau}^{*}$, for instance a counterfactual market share, this can be accomplished by choosing the structural shocks $\varepsilon_{j, \tau}^{*}$ such that the following holds

$$
\sum_{k=1}^{K} \Psi_{j k, 0} \varepsilon_{k, \tau}^{*}=F_{j, \tau}^{*}-\hat{F}_{j}
$$

where $\hat{F}_{j}$ is the $j$ th row of $\Phi_{1}^{(1)} F_{0}+\ldots+\Phi_{p}^{(1)} F_{-p+1}$.

Figure 7 shows the results of the counterfactual market share analysis beginning in January 2009 where the first purchase of MBS was recorded on the Federal Reserve balance sheet.

\footnotetext{
${ }^{12}$ The counterfactual $X_{t}$ follows from multiplying the counterfactual factors by the loadings.
} 
Note that the absense of MBS purchases are estimated to result in lower production, lower inflation, higher term spread, higher credit spread, higher unemployment, lower employment, lower capacity utilization, higher financial market volatility, and depressed lending. In short: the LSAPs of almost 2 trillion MBS seem to help avoiding the disastrous outcome of deflation, financial distress, and a much more depressed economy. Now, the response of the federal funds rate to the absense of MBS purchases may look a bit peculiar and a comment and a robustness analysis is needed. Firstly, nothing in the model prevents the federal funds rate to be negative and given the really bad state of the economy as seen by virtually all the key indicators in Figure 7 it is not surprising that the federal funds rate decreases. As a robustness analysis, however, I shut down the response of the federal funds rate to the counterfactual unconventional policy shocks in $\varepsilon_{j, \tau}^{*}$ by setting the approapriate $\Psi_{j k, 0}$ in 10 equal to zero during the 2009-2014 period. This rules out most of the negative response of the federal funds rate but without changing the conclusions. Hence, the negative federal funds rate is not the main driver of the results. ${ }^{13}$

Figure 6 about here

The results are comparable with the results of Baumeister and Benati (2013). Although they primarily consider a counterfactual analysis for 2009 only, their counterfactual unemployment rate of $10-11 \%$ at the end of 2009 is comparable to the counterfactual unemployment rate in this paper while their deflation during 2009 appears a bit later here. In addition, the dynamic factor model approach in this paper allows to study many more counterfactual responses and may thus serve as further diagnostic checks compared to the low dimensional VAR models.

A concern in constructing any counterfactual analyses is the Lucas critique and the risk that agents may change their behavior. Note, however that the Federal Reserve holdings of

\footnotetext{
${ }^{13}$ Results are available on request.
} 
MBS are determined rather discretionary by the Fed and thus less endogenous than other variables used in counterfactual VAR analyses, for instance the term spread in Baumeister and Benati (2013) and Kapetanios et al. (2012).

\subsection{Robustness analysis}

Alternative model specifications with a different lag structure, more or less factors, and a different sample are now considered as part of the robustness analysis ${ }^{14}$ Furthermore, alternative structural identification strategies are considered. Before I present the various robustness analyses, it is worth noting that the EM algorithm, as an alternative estimation method, can replicate the empirical findings of Bernanke et al. (2005) when a conventional monetary policy shock is under consideration, including the absence of the price puzzle that plagues low-dimensional VARs. ${ }^{15}$

With the ZLB, it makes little sense to consider shocks to the federal funds rate, and thus a reconciliation of the large body of empirical evidence of conventional monetary policy with the evidence of unconventional policy seems impossible. Researches have suggested replacing the federal funds rate by the so-called shadow rate which can be negative ${ }^{16}$ (see Bullard (2012) and Krippner (2013) to mention a only few). Although the use of the model-dependent shadow rate is debated among economists, it nevertheless allows yet another robustness check in which my unconventional policy results can be compared with those from structural shadow rate analyses. Consequently, I replace the federal funds rate in my panel with the shadow rate estimate in $\mathrm{Wu}$ and Xia $(\overline{2014})$ and essentially update the findings of Bernanke et al. (2005). Figure 6 shows the responses to a expansionary

\footnotetext{
${ }^{14}$ The results of the robustness analysis are intended for an online appendix "C" and related figures have a prefix "C."

${ }^{15}$ They use a two-step principal component estimation procedure as well as Bayesian methods. To compare with their results, I estimate their preferred model specification with four factors and thirteen lags using exactly their dataset as well as an expanded sample up to the end of 2007 i.e. before the ZLB period. Results are very robust and available on request. See also Bork $(2008)$ for a detailed discussion.

${ }^{16}$ The idea dates back to Black (1995), where he describes a method to calculate the value of the call option to hold cash at the zero lower bound. The call option value can be subtracted from the nominal rate (the federal funds rate) and may thus result in a negative shadow rate.
} 
shadow rate shock which are quite similar to the responses following an expansionary unconventional policy shock in Figure $5{ }^{17}$ In particular, the credit spread is reduced and the commercial and industrial loans (C\&I loans) activity is increased, implying that the credit conditions seem to be improved. Moreover, industrial production, capacity utilization, inflation (CPI-U), and employment respond positively, while unemployment is reduced.

Figure 7 about here

Lags. The impulse responses for the baseline model in Figure 5 are based on $p=10$ lags because this specification implies absense of serial correlation of the VAR residuals. However, the results are robust when the number of lags is varied. For instance, the impulse responses generally remain the same if $p=12$ or $p=6$; see Figures B.1 and B.2 in Appendix C. However, residual autocorrelation becomes a problem when $p$ is low. Specifically, the LM test of no residual autocorrelation is rejected for $p=6$ but only marginally rejected for $p=10$. Figure B.3 in Appendix C illustrates the residual autocorrelation for the baseline model and also the residual autocorrelation for the monetary policy factor for $p=6$ and $p=10$.

Sample. A shorter sample from 1959:01 to 2007:12 is considered as a robustness check of whether the structurally identifying assumptions in Table 3 are also able to identify conventional monetary policy shocks before the ZLB period. Conveniently, the weighted market share of UST and MBS would then only represent the market share of UST as the Federal Reserve did not hold MBS on its balance sheet. Accordingly, an increase in the UST share approximates an expansionary policy shock. The impulse responses in Figure B.4 in Appendix $\mathrm{C}$ are largely similar to the responses from an unconventional shock during the full sample, although the unrestricted response of the federal funds rate becomes positive

\footnotetext{
${ }^{17}$ To compare with the findings of Bernanke et al. (2005) and Wu and Xia (2014), the shadow rate shock is identified recursively.
} 
after about a year. The responses should be interpreted with some caution, as a more precise measure of the market share should probably focus on the Federal Reserve's market share of T-bills to properly account for the subset of UST that the Federal Reserve uses in the conventional policy implementation.

Identifying assumptions. For the baseline model, one of the structurally identifying assumptions for an unconventional policy shock involved a positive response of the weighted market share of UST and MBS, cf. Table 3. Results are hardly distinguishable from the baseline model if this weighted market share is replaced with a non-weighted market share, as seen in Figure B.5 in Appendix C. I also replace the weighted market share with the simple UST market share. However, the simple measure is not a representative measure of how the unconventional monetary policy was implemented during the recent crisis and the results from this particular identification strategy should probably be interpreted with caution. Figure B.6 in in Appendix C shows that the responses are largely similar to the baseline responses but generally insignificantly different from zero.

\section{Conclusion}

This paper estimates the economy-wide responses of an unconventional monetary policy shock in terms of the Federal Reserve's large-scale asset purchases. Trillion dollar asset purchases of US treasuries and mortgage backed securities have been implemented since early 2009 with the purpose of improving long-term financing conditions. How effective are the LSAPs and what are the effects on the real economy? These are important research questions, and this paper contributes with positive empirical results, new data, and a new way of identifying unconventional policy shocks. Specifically, an unconventional monetary policy shock is identified as an increase in the Federal Reserve's holdings of US treasuries and mortgage backed securities that have a financial market impact, decreases the yield spread and credit spread, improves the financial market conditions, and increases inflation 
and measures of real activity. Note that the identification of an unconventional monetary policy shock is based on a relatively large number of identifying variables that achieves a more precise identification compared to the existing approaches in the literature, wherein a smaller set of identifying variables is typically used.

I find that an unconventional shock significantly drives down the long interest rate spread and the credit spread, and improves both the financial market conditions and the commercial and industrial loans activity. The impact on the real economy is significant: industrial production, capacity utilization, inflation, and employment have significantly positive reponses, and unemployment is significantly reduced. The results are robust to alternative model specifications, and the results can be reconciled with the large body of empirical evidence on conventional monetary policy if the federal funds rate is replaced with the shadow rate.

A counterfactual analysis based on the absence of the almost two trillion MBS purchases by the Federal Reserve Bank shows that a servere downturn was avoided. An almost $2 \%$ percentage point higher unemployment rate peaking at $11 \%$ seems to be avoided. Moreover, estimates shows that deflation, higher credit spreads, depressed lending, and heightened market volatility were also avoided.

In conclusion, this paper provides evidence that unconventional US monetary policy, as implemented via large-scale asset purchases, has significantly positive effects on credit conditions and leads to an economy-wide improvement of the real economy. 


\section{A Data description}

The sample is generally 1959:01 to 2014:09, except the last series starting with "CBOE SP 100 VOLATILITY INDEX". "Tcode" denotes transformation code: 1 means the level of $x_{t}, 2$ means $\Delta x_{t}, 4$ means $\ln x_{t}$, and 5 means $\ln x_{t}-\ln x_{t-1}$.

Table 1. List of US macroeconomic and financial time series.

\begin{tabular}{|c|c|c|c|c|}
\hline & Variables & & & Tcode \\
\hline 1 & INDL PROD - FINAL & Vol SA & $2007=100$ & 5 \\
\hline 2 & INDL PROD - TOTAL & Vol SA & $2007=100$ & 5 \\
\hline 3 & INDL PROD - CONSUMER GOODS & Vol SA & $2007=100$ & 5 \\
\hline 4 & INDL PROD - DURABLE CONSUMER GOODS & Vol SA & $2007=100$ & 5 \\
\hline 5 & INDL PROD - NONDURABLE CONSUMER GOODS & Vol SA & $2007=100$ & 5 \\
\hline 6 & INDL PROD - BUSINESS EQUIPMENT & Vol SA & $2007=100$ & 5 \\
\hline 7 & INDL PROD - MATERIALS, TOTAL & Vol SA & $2007=100$ & 5 \\
\hline 8 & INDL PROD - NONENERGY DURABLE GOODS MATL. & Vol SA & $2007=100$ & 5 \\
\hline 9 & INDL PROD - NONDURB GOODS MATL. & Vol SA & $2007=100$ & 5 \\
\hline 10 & INDL PROD - DURB MFG (IPD) $)^{[1]}$ & Vol SA & spliced, $1992=100$ & 5 \\
\hline 11 & INDL PROD - NONDURB MFG (IPN) $)^{[2]}$ & Vol SA & spliced, $1992=100$ & 5 \\
\hline 12 & INDL PROD - MINING (IPMIN) ${ }^{[3]}$ & Vol SA & spliced, $1992=100$ & 5 \\
\hline 13 & INDL PROD - UTILITIES (IPUT) ${ }^{[4]}$ & Vol SA & spliced, $1992=100$ & 5 \\
\hline 14 & INDL PROD - MANUFACTURING (SIC) & Vol SA & $2007=100$ & 5 \\
\hline 15 & INDL PROD - TOTAL INDEX & Vol SA & $2007=100$ & 5 \\
\hline 16 & US INDL UTILIZATION - MANUFACTURING (SIC) & SA & & 1 \\
\hline 17 & US ISM PURCHASING MANAGERS INDEX & SA & & 1 \\
\hline 18 & US ISM MANUFACTURERS SURVEY: PRODUCTION & SA & & 1 \\
\hline 19 & US PERS INCOME, REAL (AR) (BCI 52) & Cnst price SA & 2009 PRICE & 5 \\
\hline 20 & US PERS INCOME LESS TRANSFER PAYMENTS & Cnst price SA & 2009 PRICE & 5 \\
\hline 21 & US TOTAL CIVILIAN EMPLOYMENT & Vol SA & & 5 \\
\hline 22 & US EMPLOYED, NONFARM - (16 YRS+) & Vol SA & & 5 \\
\hline 23 & US UNEMPLOYMENT RATE & SA & & 1 \\
\hline 24 & US AVERAGE DURATION OF UNEMPL. (WEEKS) & Vol SA & & 1 \\
\hline 25 & US UNEMPLOYED FOR LESS THAN 5 WEEKS & Vol SA & & 1 \\
\hline 26 & US UNEMPLOYED FOR 5 TO 14 WEEKS & Vol SA & & 1 \\
\hline 27 & US UNEMPLOYED FOR 15 WEEKS OR MORE & Vol SA & & 1 \\
\hline 28 & US UNEMPLOYED FOR 15 TO 26 WEEKS & Vol SA & & 1 \\
\hline 29 & US EMPLOYED - NONFARM INDUSTRIES TOTAL & Vol SA & & 5 \\
\hline 30 & US EMPLOYED - TOTAL PRIVATE & Vol SA & & 5 \\
\hline 31 & US EMPLOYED - GOODS-PRODUCING & Vol SA & & 5 \\
\hline 32 & US EMPLOYED - NAT RESOURCES AND MINING & Vol SA & & 5 \\
\hline 33 & US EMPLOYED - CONSTRUCTION & Vol SA & & 5 \\
\hline 34 & US EMPLOYED - MANUFACTURING & Vol SA & & 5 \\
\hline 35 & US EMPLOYED - DURABLE GOODS & Vol SA & & 5 \\
\hline 36 & US EMPLOYED - NONDURABLE GOODS & Vol SA & & 5 \\
\hline 37 & US EMPLOYED - SERVICE-PROVIDING & Vol SA & & 5 \\
\hline 38 & US EMPLOYED - TRADE, TRANSP., AND UTILITIES & Vol SA & & 5 \\
\hline 39 & US EMPLOYED - WHOLESALE TRADE & Vol SA & & 5 \\
\hline 40 & US EMPLOYED - FINANCIAL ACTIVITIES & Vol SA & & 5 \\
\hline 41 & US EMPLOYED - PRIVATE SERVICE-PROVIDING & Vol SA & & 5 \\
\hline 42 & US EMPLOYED - GOVERNMENT & Vol SA & & 5 \\
\hline 43 & US AVG WKLY HOURS - MANUFACTURING & Vol SA & & 1 \\
\hline 44 & US AVG OVERTIME HOURS - MANUFACTURING & Vol SA & & 1 \\
\hline 45 & US ISM MANUFACTURERS SURVEY: EMPLOYMENT & SA & & 1 \\
\hline 46 & US PERS CONSUMPTION EXPEND (AR) & Curr price SA & & 5 \\
\hline 47 & US PERS CONSUMPTION EXPEND - DURB (AR) & Curr price SA & & 5 \\
\hline 48 & US PERS CONSUMPTION EXPEND - NONDURB (AR) & Curr price SA & & 5 \\
\hline 49 & US PERS CONSUMPTION EXPEND - SERVICES (AR) & Curr price SA & & 5 \\
\hline 50 & US PCE: DURB - NEW AUTOS & Curr price SA & & 5 \\
\hline 51 & US NEW PRIV HOUSING STARTED & Vol SA & & 4 \\
\hline 52 & US HOUSING STARTED - NORTHEAST (AR) & Vol SA & & 4 \\
\hline 53 & US HOUSING STARTED - MIDWEST (AR) & Vol SA & & 4 \\
\hline 54 & US HOUSING STARTED - SOUTH (AR) & Vol SA & & 4 \\
\hline
\end{tabular}


Variables

\begin{tabular}{|c|c|c|c|c|}
\hline 55 & 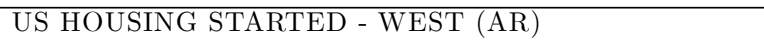 & Vol SA & & 4 \\
\hline 56 & US BUILD PERMITS TO NEW PRIV HOUSING & Vol SA & & 4 \\
\hline 57 & US ISM MANUFACTURERS SURVEY: INVENT & Not SA & & 1 \\
\hline 58 & US ISM MANUFACTURERS SURVEY: NEW ORDERS & SA & & 1 \\
\hline 59 & US ISM MANUFACTURERS SURVEY: DELIVERIES & SA & & 1 \\
\hline 60 & US NEW ORDERS - CONSUMER GOODS (BCI 8) & Cnst price SA & 1982 PRICES & 5 \\
\hline 61 & US NEW ORDERS - NONDEFENSE CAP (BCI 27) & Cnst price SA & 1982 PRICES & 5 \\
\hline 62 & NYSE STOCK PRICE INDEX & & spliced, $1965=100$ & 5 \\
\hline 63 & US SP COMPOSITE INDEX (EP) & & $(1941-43=100)$ & 5 \\
\hline 64 & SP 500 STOCK PRICE INDEX: INDUSTRIALS ${ }^{[5]}$ & & spliced & 5 \\
\hline 65 & US SP 500 COMPOSITE - DIVIDEND YLD & & & 1 \\
\hline 66 & US SP 500 COMPOSITE - REAL P/E RATIO & & & 1 \\
\hline 67 & SW SWISS FRANCS TO USD & & & 5 \\
\hline 68 & JP JAPANESE YEN TO US USD & Interest Rates & & 5 \\
\hline 69 & UK US USD TO 1 & Interest Rates & & 5 \\
\hline 70 & CN EXCHANGE RATE: CURRENCY PER USD & Not SA & $\mathrm{USD} / \mathrm{CAD}$ & 5 \\
\hline 71 & US FEDERAL FUNDS RATE (AVG.) & & & 1 \\
\hline 72 & US T-BILL 3 MONTH & Interest Rates & & 1 \\
\hline 73 & US T-BILL 6 MONTH & Interest Rates & & 1 \\
\hline 74 & US TREASURY YIELD CONST. MAT. - 1 YEAR & Interest Rates & & 1 \\
\hline 75 & US TREASURY YIELD CONST. MAT. - 5 YEAR & Interest Rates & & 1 \\
\hline 76 & US TREASURY YIELD CONST. MAT. - 10 YEAR & Interest Rates & & 1 \\
\hline 77 & US CORPORATE BOND YIELD - MOODYS AAA & Interest Rates & AVRGE & 1 \\
\hline 78 & US CORPORATE BOND YIELD - MOODYS BAA & Interest Rates & AVRGE & 1 \\
\hline 79 & US T-BILL 3 MONTH & Interest Rates & & 1 \\
\hline 80 & US T-BILL 6 MONTH & Interest Rates & & 1 \\
\hline 81 & US TREASURY YIELD CONST. MAT. - 1 YEAR & Interest Rates & & 1 \\
\hline 82 & US TREASURY YIELD CONST. MAT. - 5 YEAR & Interest Rates & & 1 \\
\hline 83 & US TREASURY YIELD CONST. MAT. - 10 YEAR & Interest Rates & & 1 \\
\hline 84 & US CORPORATE BOND YIELD - MOODYS AAA & Interest Rates & AVRGE & 1 \\
\hline 85 & US CORPORATE BOND YIELD - MOODYS BAA & Interest Rates & AVRGE & 1 \\
\hline 86 & BAA - 10YR & Interest Rates & & 1 \\
\hline 87 & US MONEY SUPPLY M1 & Curr price SA & & 5 \\
\hline 88 & US MONEY SUPPLY M2 & Curr price SA & & 5 \\
\hline 89 & US MONEY SUPPLY M2 (BCI 106) & Cnst price SA & 2009 PRICE & 5 \\
\hline 90 & US MONETARY BASE CURN & Curr price NSA & & 5 \\
\hline 91 & US COML AND INDL. LOANS OUTSTAND. & Cnst price SA & 2009 PRICE & 5 \\
\hline 92 & US COML BANK ASSETS-COML. AND INDL LOANS & $\mathrm{SA}$ & & 1 \\
\hline 93 & US NONREVOLV CONS CREDIT OUTSTAND & Curr price SA & & 5 \\
\hline 94 & OUTSTANDING MORTGAGE DEBT ${ }^{[6]}$ & yearly growth & & 1 \\
\hline 95 & FRB ASSETS: UST, MORTG., FDRL. AGENCY & yearly growth & & 1 \\
\hline 96 & FED MARKET SHARE UST RISK ${ }^{[7]}$ & yearly change & & 1 \\
\hline 97 & FED MARKET SHARE UST AND MBS RISK ${ }^{[8]}$ & yearly change & & 1 \\
\hline 98 & US ISM MANUFACTURERS SURVEY: PRICES PAID & SA & & 1 \\
\hline 99 & US PPI - FINISHED GOODS & Price index SA & $1982=100$ & 5 \\
\hline 100 & US PPI - FINISHED CONSUMER GOODS & Price index SA & $1982=100$ & 5 \\
\hline 101 & US PPI - INTERMED. MATL, SUPPL AND COMP & Price index SA & $1982=100$ & 5 \\
\hline 102 & US PPI - CRUDE MATERIALS & Price index SA & $1982=100$ & 5 \\
\hline 103 & US CPI - ALL URBAN: ALL ITEMS & Price index SA & $1982-1984=100$ & 5 \\
\hline 104 & US CPI - APPAREL & Price index $\mathrm{SA}$ & $1982-1984=100$ & 5 \\
\hline 105 & US CPI - TRANSPORTATION & Price index SA & $1982-1984=100$ & 5 \\
\hline 106 & US CPI - MEDICAL CARE & Price index SA & $1982-1984=100$ & 5 \\
\hline 107 & US CPI - COMMODITIES & Price index SA & $1982-1984=100$ & 5 \\
\hline 108 & US CPI - DURB & Price index SA & $1982-1984=100$ & 5 \\
\hline 109 & US CPI - SERVICES & Price index SA & $1982-1984=100$ & 5 \\
\hline 110 & US CPI - ALL ITEMS LESS FOOD & Price index SA & $1982-1984=100$ & 5 \\
\hline 111 & US CPI - ALL ITEMS LESS SHELTER & Price index SA & $1982-1984=100$ & 5 \\
\hline 112 & US CPI - ALL ITEMS LESS MEDICAL CARE & Price index SA & $1982-1984=100$ & 5 \\
\hline 113 & US AVG HRLY EARN - CONSTRUCTION & Curr price SA & USD/Hour & 5 \\
\hline 114 & US AVG HRLY EARN - MANUFACTURING & Curr price SA & USD/Hour & 5 \\
\hline 115 & US CONSUMER CONFIDENCE - EXPECTATIONS & Price index SA & $1966 \mathrm{M} 1=100$ & 1 \\
\hline 116 & GARCH VOL EST ${ }^{[9]}$ & & & 1 \\
\hline 117 & CBOE SP 100 VOLATILITY INDEX & & 1986:06 - & 1 \\
\hline 118 & FRB CHICAGO NAT FIN CONDITION INDEX & & 1973:01- & 1 \\
\hline 119 & KANSAS CITY FINANCIAL STRESS INDEX & & 1990:02- & 1 \\
\hline
\end{tabular}




\begin{tabular}{lll}
\hline 120 & TED SPREAD & $1986: 01-$ \\
121 & US AVG CONS EXPECT FOR BUS COND. (INV) & $1978: 02-$ \\
122 & ML MOVE BOND VOLATILITY INDEX & $1988: 06-$ \\
123 & ADS BUS CONDITION INDEX (INV) & 1 \\
\end{tabular}

Notes: Proprietary data sources: Datastream. Public sources: Federal Reserve Economic Data (FRED). Federal Reserve Archive (FRASER). Federal Housing Finance Agency. Securities Industry and Financial Markets Association (SIFMA). Economic report(s) of the President. Treasury Bulletin.

Variable specific notes:

[1] Durable Manufacturing(disc. 2002) is spliced with durable manufactures (starting 1972).

[2] Nondurable Manufacturing(disc. 2002) is spliced with nondurable manufactures (starting 1972).

[3] Mining (disc. 2002) is spliced with Mining, NAICS=21 (starting 1972).

[4] Utilities (disc. 2002) is spliced with Electric and Gas Utilities (starting 1972).

[5] NYSE common stock price index composite (disc.) is spliced with NYSE COMPOSITE - PRICE INDEX (starting 1966)

${ }^{[6]}$ Disaggregated from quarterly to monthly using interpolation.

[7] This is the Federal Reserve's share of the total market duration of USTs (interest rate risk). The Federal Reserve's UST portfolio is decomposed into holdings of USTs of various time to maturity; specifically into: $<15$ day T-bills, $15-90$ day T-bills, 1 to 5 year T-notes, 5 to 10 year T-notes, and $>10$ year T-bonds. The same applies for the privately held market portfolio. See table FD-5 in the Treasury Bulletin for this decomposition. Next, I multiply these holdings with a fixed duration measure and then calculate the total portfolio duration. Finally, I calculate the ratio of the Federal Reserve's UST portfolio duration relative to the total market duration.

[8] Same calculations as for the Federal Reserve's share of total market duration of USTs, except that holdings of Mortgage Backed Securities are now added to the portfolios. The duration of MBS is the average of the option-adjusted duration for 15-year and 30-year Freddie Mac current coupon MBS at each month.

[9] This is the volatility estimate from a $\operatorname{GARCH}(1,1)$ estimated on the NYSE stock index. 


\section{B Zero and sign restrictions in a dynamic factor model}

The algorithm of Arias et al. (2014) for imposing zero and sign restrictions on the impulse responses from VARs are now slightly modified to allow for similar restrictions on DFMs. Arias et al. (2014) extend the efficient sign restriction algorithm of Rubio-Ramírez et al. (2010) to allow for zero restrictions, and ARW forcefully argue that whenever sign restrictions are combined with zero restrictions, it becomes crucial to condition the draws on the zero restrictions. Otherwise, additional sign restrictions are implicitly imposed.

The notation is first presented and then the algorithm. The number of variables in the VAR is $r$ and $p$ denotes the lags. The structural VAR parameters generally carry the letter $A$, with $A_{0}$ denoting the impact matrix and $A_{1}, . ., A_{p}$ denoting the autoregressive parameters, while the structural shocks are mean zero and the variance is $E\left[\varepsilon_{t} \varepsilon_{t}^{\top}\right]=I_{r}$. The reduced form parameters are then $\Phi_{1}=A_{0}^{-1} A_{1}, \ldots, \Phi_{p}=A_{0}^{-1} A_{p}$ as seen in (1) with the reduced form residuals $u_{t}$ characterized by $E\left[u_{t} u_{t}^{\top}\right]=A_{0}^{-1}\left(\mathcal{A}_{0}^{-1}\right)^{\top}=\Sigma_{u}$. The reduced form companion matrix without any subscript, $\Phi$, is of dimension $r p \times r p$.

The impulse response of the $i$ th variable (factor) in the VAR to the $j$ th structural shock at horizon $h$ is seen in row $i$, column $j$ in $\Theta_{h}$ from the structural VMA representation ${ }^{18}$,

$$
F_{t}=\sum_{h=1}^{\infty} \Theta_{h} \varepsilon_{t-h}=J \Phi^{h} J^{\top} \mathcal{A}_{0}^{-1}
$$

where $J$ is an $r p \times r$ selection matrix with zeros except for the top $r \times r$ matrix, which is $I_{r}$, and where $\Phi^{h}$ is the companion matrix to the power of $h$. The response of the $n$th observed variable to the $j$ th structural shock at horizon $h$ is seen in row $n$, column $j$ in $\Psi_{h}:$

$$
X_{t}=\sum_{h=1}^{\infty} \Psi_{h} \varepsilon_{t-h}=\Lambda J^{\top} \Phi^{h} J \mathcal{A}_{0}^{-1}
$$

Consider restricting the VAR impulse responses in (11) by zero and sign restrictions for a

\footnotetext{
${ }^{18} \Theta_{i}$ obeys a recursion; see Lütkepohl $(2005)$ chapter 2 for the details.
} 
maximum of $h$ periods and stack the responses in the $r h \times r$ dimensional matrix $F(\mathcal{A})$, where $A$ emphasizes the structural parameters. Alternatively, a subset $r \leq \rho \leq N$ of the panel impulse responses in (12) are stacked in the $\rho h \times r$ matrix $X(\mathcal{A})$. The $z_{j}$ zero restrictions imposed on the $j$ th structural shock are represented by matrices $Z_{j}$, whereas the $s_{j} \operatorname{sign}$ restrictions are represented by the matrix $S_{j}$. Thus, the zero restrictions are satisfied if $Z_{j} F(\mathcal{A}) e_{j}=0$, where $e_{j}$ is the $j$ th column of $I_{r}$; alternatively for an appropriate $Z_{j}$, $Z_{j} X(\mathcal{A}) e_{j}=0$. Similarly, for the sign restrictions, $S_{j} F(\mathcal{A}) e_{j}>0$. Note that the impulse responses are only set identified, as any orthogonal $r \times r$ matrix $Q, S_{j} F(\mathcal{A} Q) e_{j}>0$ will also satisfy the restrictions.

The idea is to generate a large number of orthogonal matrices $Q$, but where the generation of these matrices takes into account the zero restrictions. Any $Q$ that do not satisfy the zero and sign restrictions will be discarded, while the $Q$ that satisfy the restrictions will be kept:

$$
\begin{aligned}
& Z_{j} \mathcal{F}(\mathcal{A} Q) e_{j}=Z_{j} \mathcal{F}(\mathcal{A}) Q e_{j}=Z_{j} \mathcal{F}(\mathcal{A}) q_{j}=0 \\
& S_{j} \mathcal{F}(\mathcal{A} Q) e_{j}=S_{j} \mathcal{F}(\mathcal{A}) q_{j}>0
\end{aligned}
$$

or for appropriate $Z_{j}$ and $S_{j}$

$$
\begin{aligned}
& Z_{j} \mathcal{X}(\mathcal{A} Q) e_{j}=Z_{j} \mathcal{X}(\mathcal{A}) q_{j}=0 \\
& S_{j} \mathcal{X}(\mathcal{A} Q) e_{j}=S_{j} \mathcal{X}(\mathcal{A}) q_{j}>0
\end{aligned}
$$

The following algorithm from ARW shows how to draw the structural parameters $A$ conditional on zero and sign restrictions. Without loss of generality, the zero restrictions are imposed on the first $k$ variables, where $1 \leq k \leq r$ and $z_{j}$ need to satisfy $z_{j} \leq n-k$. The first step in the algorithm is then to obtain the $r \times k$ matrix $Q_{k}$ corresponding to the zero restrictions and then conditional on $Q_{k}$ to draw the remaining $Q_{n-k}$ matrix, such that for each draw $Q=\left[\begin{array}{ll}Q_{k} & Q_{n-k}\end{array}\right]$.

Algorithm 1 Given the reduced form VAR parameters $\left(\Phi, \Sigma_{u}\right)$ and a mapping $\hat{h}\left(\Phi, \Sigma_{u}, I_{r}\right)$ 
to the structural parameters $A$, where $\hat{h}$ could involve computing the Cholesky decomposition or a symmetric and positive definite square root matrix, the $Q_{k}$ part of $Q$ is first drawn and secondly the remaining $Q_{n-k}$.

1. Apply a Gibbs sampler to draw from the uniform distribution of $Q_{k}$ conditional on $Z_{j} F(\mathcal{A}) q_{j}=0$ for $1 \leq j \leq k$. Given the structural parameters in $A$ and $q_{1}^{(i+1)}, . ., q_{j-1}^{(i+1)}, q_{j+1}^{(i)}, \ldots, q_{k}^{(i)}$ :

(a) Let $\hat{N}_{j}^{(i+1)}$ denote the orthonormal basis for the null space of

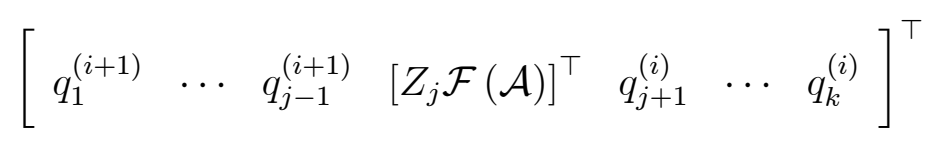

(b) Upon drawing $\tilde{x}_{j}^{(i+1)}$ from a standard normal, compute $q_{j}^{(i+1)}$ from

$$
q_{j}^{(i+1)}=\frac{\left[\hat{N}_{j}^{(i+1)} 0_{r, r-\hat{r}_{j}^{(i+1)}}\right] \tilde{x}_{j}^{(i+1)}}{\left\|\left[\hat{N}_{j}^{(i+1)} 0_{r, r-\hat{r}_{j}^{(i+1)}}\right] \tilde{x}_{j}^{(i+1)}\right\|}
$$

where $\hat{r}_{j}^{(i+1)}$ is the rank of $\hat{N}_{j}^{(i+1)}$.

2. Step $1 a$ to $1 b$ are repeated $L$ times to ensure that $q_{1}^{(L)}, . ., q_{k}^{(L)}$ converges to the uniform distribution of $Q_{k}$ conditional on $Z_{j} F(\mathcal{A}) q_{j}=0$. The convergence is faster if the Gibbs sampler is filled in with the following starting values. Specifically, $\tilde{N}_{j}^{(0)}$ is the orthonormal basis of the null space of

$$
\left.\left[\begin{array}{llll}
q_{1}^{(0)} & \cdots & q_{j-1}^{(0)} & {\left[Z_{j} \mathcal{F}(\mathcal{A})\right.}
\end{array}\right]^{\top}\right]^{\top}
$$

and upon drawing $\tilde{x}_{j}^{(0)}$, starting values for the q's can be calculated from:

$$
q_{j}^{(0)}=\frac{\left[\tilde{N}_{j}^{(0)} 0_{r, r-\tilde{r}_{j}^{(0)}}\right] \tilde{x}_{j}^{(0)}}{\left\|\left[\tilde{N}_{j}^{(0)} 0_{r, r-\tilde{r}_{j}^{(0)}}\right] \tilde{x}_{j}^{(0)}\right\|}
$$


Remark 2 Alternatively, $\left[Z_{j} \mathcal{F}(\mathcal{A})\right]^{\top}$ corresponding to 13 is replaced by $\left[\Lambda Z_{j} \mathcal{F}(\mathcal{A})\right]^{\top}$ corresponding to (14).

3. Draw the remaining $Q_{n-k}$ conditional on $Q_{k}$ constructed from the converged $q_{1}^{(L)}, \ldots, q_{k}^{(L)}$. Let $\tilde{X}_{r-k}$ be a $(r-k) \times(r-k)$ random matrix where each element is iid $\sim N(0,1)$. Let $N_{k}$ denote the orthonormal basis for the null space of $Q_{k}$ and compute the $Q R$ decomposition of $N_{k} \tilde{X}_{r-k}$, i.e.

$$
\begin{aligned}
\mathcal{Q R} & =N_{k} \tilde{X}_{r-k} \\
Q_{n-k} & =\mathcal{Q}
\end{aligned}
$$

from which the complete orthogonal matrix $Q$ can be assembled as $Q=\left[\begin{array}{ll}Q_{k} & Q_{n-k}\end{array}\right]$.

4. Keep the draw if $S_{j} F(\mathcal{A}) q_{j}>0$ for all structural shocks identified with sign restrictions. Note, the zero restrictions are already satisfied.

Remark 3 Again, $S_{j} F(\mathcal{A}) q_{j}>0$ may be replaced by $S_{j} X(\mathcal{A}) q_{j}>0$.

5. Return to step 1 and repeat until the desired number of draws has been obtained. 


\section{References}

Aguilar, O. \& West, M. (2000), 'Bayesian dynamic factor models and portfolio allocation', Journal of Business and Economic Statistics 3(18), 338-357.

Arias, J. E., Rubio-Ramirez, J. F. \& Waggoner, D. F. (2014), Inference Based on SVARs Identified with Sign and Zero Restrictions: Theory and Applications, International Finance Discussion Papers, Board of Governors of the Federal Reserve System (U.S.) 1100, Board of Governors of the Federal Reserve System (U.S.).

Bai, J. \& Ng, S. (2007), 'Determining the number of primitive shocks in factor models', Journal of Business 85 Economic Statistics 25, 52-60.

Bai, J. \& Wang, P. (2014a), 'Identification and bayesian estimation of dynamic factor models', Journal of Business and Economic Statistics (forthcoming), 1-53.

Bai, J. \& Wang, P. (2014b), 'Identification theory for high dimensional static and dynamic factor models', Journal of Econometrics 178(2), 794 - 804.

Bates, B. J., Plagborg-Møller, M., Stock, J. H. \& Watson, M. W. (2013), 'Consistent factor estimation in dynamic factor models with structural instability', Journal of Econometrics $\mathbf{1 7 7}(2), 289-304$.

Baumeister, C. \& Benati, L. (2013), 'Unconventional Monetary Policy and the Great Recession: Estimating the Macroeconomic Effects of a Spread Compression at the Zero Lower Bound', International Journal of Central Banking 9(2), 165-212.

Bernanke, B. S., Boivin, J. \& Eliasz, P. (2005), 'Measuring the effects of monetary policy: a factor-augmented vector autoregressive (FAVAR) approach', The Quarterly Journal of Economics pp. 387-422.

Binning, A. (2013), Underidentified svar models: A framework for combining short and long-run restrictions with sign-restrictions, Working Paper 2013/14, Norges Bank. 
Bork, L. (2008), Estimating US monetary policy shocks using a factor-augmented vector autoregression: An EM algorithm approach. CREATES Research Paper 2009-11.

Bork, L., Dewachter, H. \& Houssa, R. (2009), Identification of Macroeconomic Factors in Large Panels, CREATES Research Papers 2009-43, School of Economics and Management, University of Aarhus.

Bullard, J. (2012), Shadow interest rates and the stance of U.S. monetary policy, Speech at the Annual Corporate Finance Conference, Olin Business School, Washington University, St. Louis.

Canova, F. \& Nicolo, G. D. (2002), 'Monetary disturbances matter for business fluctuations in the G-7', Journal of Monetary Economics, Elsevier 49(6), 1131-1159.

D’Amico, S., English, W., López-Salido, D. \& Nelson, E. (2012), 'The Federal Reserve's large-scale asset purchase programs: Rationale and effects', The Economic Journal (122), F415-F446.

D'Amico, S. \& King, T. B. (2013), 'Flow and stock effects of large-scale treasury purchases: Evidence on the importance of local supply', Journal of Financial Economics 108(2), 425-448.

Dempster, A. P., Laird, N. M. \& Rubin, D. B. (1977), 'Maximum likelihood from incomplete data via the EM algorithm', Journal of the Royal Statistical Society 39(1), 1-38.

Doz, C., Giannone, D. \& Reichlin, L. (2012), 'A quasi maximum likelihood approach for large approximate dynamic factor models', Review of Economics and Statistics 94, 10141024.

Faust, J. (1998), 'The robustness of identified var conclusions about money', CarnegieRochester Conference Series on Public Policy 49, 207-244. 
Forni, M. \& Gambetti, L. (2010), 'The dynamic effects of monetary policy: A structural factor model approach', Journal of Monetary Economics 57(2), 203-216.

Forni, M., Hallin, M., Lippi, M. \& Reichlin, L. (2000), 'The generalized dynamicfactor model: Identification and estimation', The Review of Economics and Statistics 82(4), 540-554.

Forni, M., Hallin, M., Lippi, M. \& Reichlin, L. (2004), 'The generalised dynamic factor model: consistency and rates', Journal of Econometrics 119(2), 231-255.

Forni, M., Hallin, M., Lippi, M. \& Reichlin, L. (2005), 'The generalized dynamic factor model: one sided estimation and forecasting', Journal of the American Statistical Association 100(471), 830-840.

Fry, R. \& Pagan, A. (2011), 'Sign restrictions in structural vector autoregressions: A critical review', Journal of Economic Literature 49(4), 938-60.

Gagnon, J., Raskin, M., Remache, J. \& Sack, B. (2011), 'The Financial Market Effects of the Federal Reserve's Large-Scale Asset Purchases', International Journal of Central Banking 7(1), 3-43.

Gambacorta, L., Hofmann, B. \& Peersman, G. (2014), 'The Effectiveness of Unconventional Monetary Policy at the Zero Lower Bound: A Cross-Country Analysis', Journal of Money, Credit and Banking 46(4), 615-642.

Geweke, J. (1977), The dynamic factor analysis of economic time series, in D. J. Aigner \& A. S. Golderger, eds, 'Latent Variables in Socioeconomic Models', North Holland.

Geweke, J. F. \& Singleton, K. J. (1981), 'Maximum likelihood "confirmatory" factor analysis of economic time series', International Economic Review 22(1), 37-54.

Geweke, J. \& Zhou, G. (1996), 'Measuring the pricing error of the arbitrage pricing theory', Review of Financial Studies $\mathbf{9}(2), 557-587$. 
Glick, R. \& Leduc, S. (2012), 'Central bank announcements of asset purchases and the impact on global financial and commodity markets', Journal of International Money and Finance 31(8), $2078-2101$.

Hallin, M. \& Liska, R. (2007), 'Determining the number of factors in the generalized factor model', Journal of the American Statistical Association 102, 603-617.

Joyce, M., Miles, D., Scott, A. \& Vayanos, D. (2012), 'Quantitative Easing and Unconventional Monetary Policy Ü an Introduction', Economic Journal 122(564), F271-F288.

Jungbacker, B. \& Koopman, S. J. (2014), 'Likelihood-based dynamic factor analysis for measurement and forecasting', The Econometrics Journal (17), 1-21.

Kapetanios, G., Mumtaz, H., Stevens, I. \& Theodoridis, K. (2012), 'Assessing the economywide effects of quantitative easing', Economic Journal 122(564), F316-F347.

Kilian, L. (2013), Structural vector autoregressions, in N. Hashimzade \& M. A. Thornton, eds, 'Handbook of Research Methods and Applications in Empirical Macroeconomics', Edward Elgar, chapter 22.

Krippner, L. (2013), A tractable framework for zero lower bound Gaussian term structure models, Reserve Bank of New Zealand Discussion Paper Series DP2013/02, Reserve Bank of New Zealand.

Krishnamurthy, A. \& Vissing-Jorgensen, A. (2011), 'The Effects of Quantitative Easing on Interest Rates: Channels and Implications for Policy', Brookings Papers on Economic Activity 43(2 (Fall)), 215-287.

Lenza, M., Pill, H. \& Reichlin, L. (2010), 'Monetary policy in exceptional times', Economic Policy 25, 295-339.

Luetkepohl, H. (2011), Vector Autoregressive Models, Economics Working Papers ECO2011/30, European University Institute. 
Lütkepohl, H. (2005), New Introduction to Multiple Time Series Analysis, Springer, Berlin.

Mountford, A. \& Uhlig, H. (2009), 'What are the effects of fiscal policy shocks?', Journal of Applied Econometrics 24(6), 960-992.

Ross, S. A. (1976), 'The arbitrage theory of capital asset pricing', Journal of Economic Theory 13, 341-360.

Rubio-Ramírez, J. F., Waggoner, D. F. \& Zha, T. (2010), 'Structural Vector Autoregressions: Theory of Identification and Algorithms for Inference', Review of Economic Studies $77(2), 665-696$.

Sargent, T. J. (1989), 'Two models of measurements and the investment accelerator', Journal of Political Economy 97(2), 251-287.

Sargent, T. J. \& Sims, C. A. (1977), Business cycle modeling without pretending to have too much a priori economic theory, in C. A. Sims, ed., 'New Methods in Business Cycle Research', Federal Reserve Bank on Minneapolis, pp. 45-110.

Shumway, R. H. (2000), 'Dynamic mixed models for irregularly observed time series', $R e$ senhas Reviews of the Institute of Mathematics and Statistics 4(4), 433-456.

Shumway, R. H. \& Stoffer, D. S. (1982), 'An approach to time series smoothing and forecasting using the EM algorithm', Journal of Time Series Analysis 3, 253-226.

Stock, J. H. \& Watson, M. W. (2002a), 'Forecasting using principal components from a large number of predictors', Journal of the American Statistical Association 97, 11671179.

Stock, J. H. \& Watson, M. W. (2002b), 'Macroeconomic forecasting using diffusion indexes', Journal of Business Economics and Statistics XX:II, 147-162. 
Stock, J. \& Watson, M. (2009), Forecasting in Dynamic Factor Models Subject to Structural Instability, Oxford University Press, chapter 7, pp. 1-57.

Swanson, E. T. \& Williams, J. C. (2014), 'Measuring the effect of the zero lower bound on medium- and longer-term interest rates', American Economic Review 104(10), 3154-85.

Uhlig, H. (2005), 'What are the effects of monetary policy on output? Results from an agnostic identification procedure', Journal of Monetary Economics 52(2), 381-419.

Watson, M. W. \& Engle, R. F. (1983), 'Alternative algorithms for the estimation of dynamic factor, MIMIC and varying coefficient regression models', Journal of Econometrics 23(3), 385-400.

Wu, J. C. \& Xia, F. D. (2014), Measuring the macroeconomic impact of monetary policy at the zero lower bound, Working Paper 20117, National Bureau of Economic Research. 
Table 2. Summary of important QE announcements by the Federal Reserve

\begin{tabular}{lll}
\hline \hline Date & QE & Description of event \\
\hline \hline November 25, 2008 & QE1 & $\begin{array}{l}\text { LSAP announcement. Fed will purchase up to 100 bn. } \\
\text { GSE and 500 bn. MBS }\end{array}$ \\
\hline December 1, 2008 & QE1 & $\begin{array}{l}\text { Bernanke: Could purchase UST og MBS in } \\
\text { substantial quantities. }\end{array}$ \\
\hline December 16, 2008 & QE1 & $\begin{array}{l}\text { Federal funds rate cut. Fed suggests to extend QE to } \\
\text { USTs }\end{array}$ \\
\hline January 28, 2009 & QE1 & Fed stands ready to expand QE by buying USTs \\
\hline March 18, 2009 & QE1 & $\begin{array}{l}\text { The Fed will purchase 300 bn. in USTs and additional } \\
\text { 750 bn. MBS and 100 bn. GSE }\end{array}$ \\
\hline September 23, 2009 & QE1 & Agency debt and MBS will end 2010:Q1 \\
\hline November 4, 2009 & QE1 & Agency debt purchases downsized to 175 bn. \\
\hline August 10, 2010 & QE2 & $\begin{array}{l}\text { The Fed will reinvest principal payments form LSAPs } \\
\text { in USTs }\end{array}$ \\
\hline August 27, 2010 & QE2 & $\begin{array}{l}\text { Bernanke: "role for additional QE should further } \\
\text { action prove necessary". }\end{array}$ \\
\hline September 21, 2010 & QE2 & $\begin{array}{l}\text { FOMC statement: Additional accommodation if } \\
\text { needed }\end{array}$ \\
\hline November 3, 2010 & QE2 & Fed will buy 600 bn. of UST with 75 bn./month \\
\hline September 21, 2011 & Twist & $\begin{array}{l}\text { Fed will purchase } 400 \text { bn. of long UST and sell short } \\
\text { UST }\end{array}$ \\
\hline June 20, 2012 & Twist & $\begin{array}{l}\text { Fed continues with operation Twist (MEP) in 2012 } \\
\text { with 45 bn. UST/month }\end{array}$ \\
\hline September 13, 2012 & QE3 & $\begin{array}{l}\text { Fed will purchase } 85 \text { bn. of UST in addition to } 40 \text { bn. } \\
\text { MBS per month }\end{array}$ \\
\hline December 12, 2012 & QE3 & $\begin{array}{l}\text { Fed will purchase } 45 \text { bn. of UST in addition to } 40 \text { bn. } \\
\text { MBS per month }\end{array}$ \\
\hline December 18, 2013 & QE2 & Fed cuts purchases of MBS by 10 bn. to 75 bn. \\
\hline
\end{tabular}


Table 3. Sign restrictions for the baseline dynamic factor model

\begin{tabular}{|c|c|c|c|c|c|c|}
\hline & & Shocks: & uMP & cMP & $\mathbf{A S}$ & $\mathrm{AD}$ \\
\hline & Series: & & & & & \\
\hline Aggregate inflation: & CPI-U all & & + & + & - & + \\
\hline \multirow[t]{2}{*}{ Aggregate output: } & Empl: total & & $*$ & + & + & + \\
\hline & Unemp: All. ${ }^{\dagger}$ & & * & * & $*$ & $*$ \\
\hline \multirow[t]{2}{*}{ Unconventional policy } & Risk. share & & + & $*$ & $*$ & $*$ \\
\hline & FRB assets & & + & $*$ & $*$ & $*$ \\
\hline Conventional policy & Fed funds & & 0 & - & $*$ & + \\
\hline Financial conditions & Vix & & - & $*$ & * & $*$ \\
\hline Credit conditions & Baa - 10y & & - & * & $*$ & $*$ \\
\hline
\end{tabular}

Note: The first column contains the theoretical economic concepts that the structural shocks should affect. $(\dagger)$ : I remain agnostic about the unemployment rate when considering the unconventional monetary policy shock. The second column shows the restricted observed series; see variable numbers 106, 2, 29, 23, 98, 71, 120, and 88 in Appendix A The last three columns show the shocks and the identifying restrictions. 
Figure 1. Interest rates and key economic variables during the recent crisis.
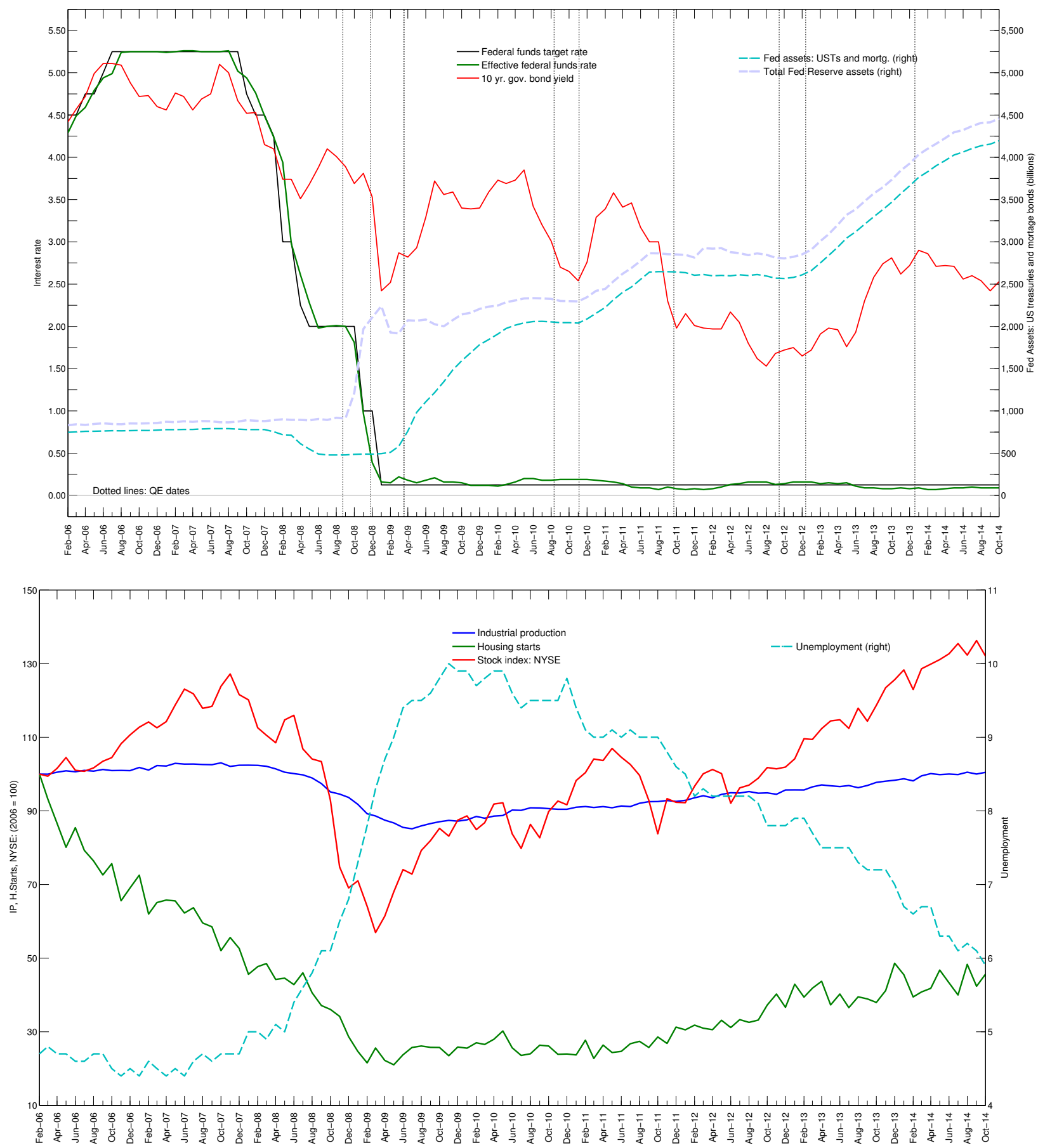

The upper panel shows the federal funds rate(s) and the 10-year government bond yield on the left scale. On the right scale is shown (i) the Federal Reserve Bank holdings of UST and MBS, and (ii) Total Federal Reserve Assets. The vertical lines show QE announcement dates: Aug. 22, 2008; Nov. 25, 2008; Mar. 18, 2009; Oct. 10, 2010; Nov. 3, 2010; Sep. 21, 2011; Sep. 13, 2012; Dec. 12, 2012; Dec 18, 2013. The lower panel shows total industrial production, housing startss and the New York Stock Exchange index on the left scale; all normalized to $2006: 01=100$. The right scale shows the unemployment rate. 
Figure 2. 10-year government bond yield, credit spread, and LSAP activity.

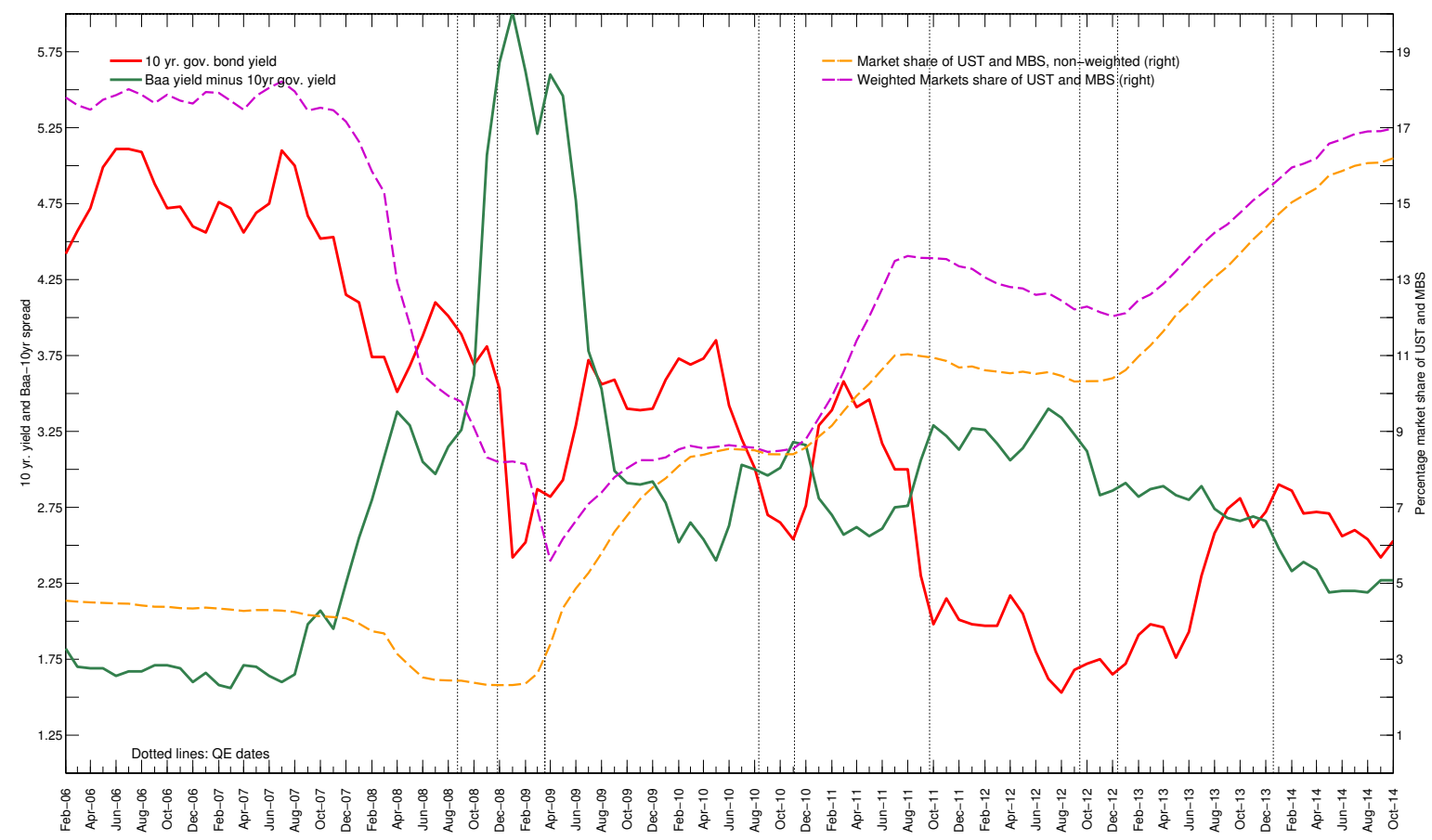

On the left axis is shown the 10-year government bond yield and the credit spread (Baa yield - 10yr gov. yield). On the right axis is shown (i) the Federal Reserve's market share of US treasuries (UST) + mortgage backed securities (MBS), and (ii) a weighted market share of US treasuries and mortgage backed securities, respectively. The non-weighted market share simply measures the Federal Reserves's holdings of UST and MBS relative to the total outstanding value. The weighted market share is weighted by the relative balance sheet size $\left(B_{i}\right)$, as a fraction $B_{U S T} /\left(B_{U S T}+B_{M B S}\right)$ of the UST market share and 1 minus this fraction of the market share of MBS. 


\section{Figure 3. Total Federal Reserve assets and main asset components.}
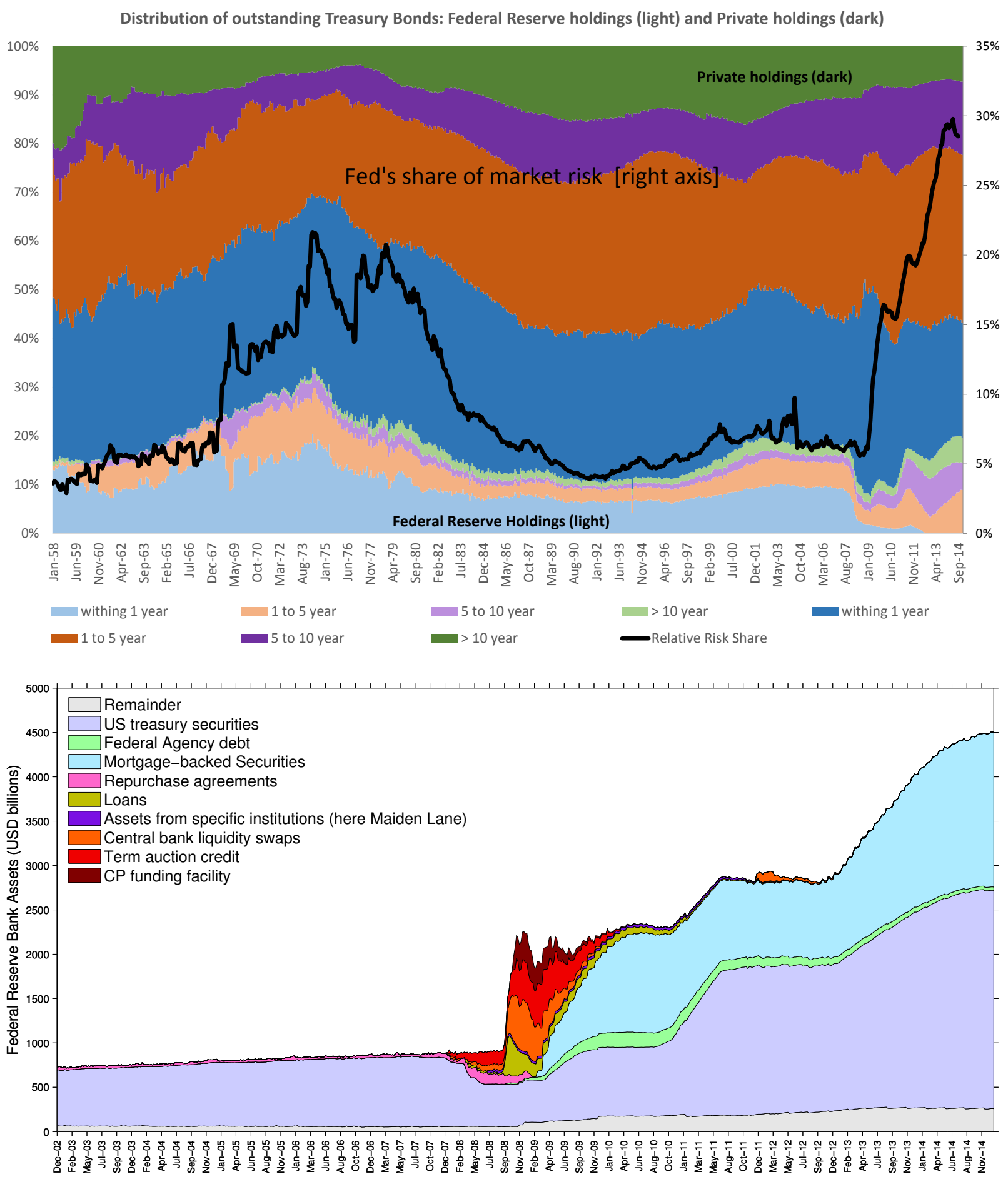

The upper panel shows the monthly total value of the Federal Reserve's holdings and private holdings of UST decomposed into maturity buckets. Furthermore, on the right axis is shown a measure of the Federal Reserve's relative share of UST and MBS risk. For each maturity bucket the UST dollar duration is calculated together with the dollar duration of MBS (based on a single and common duration measure). The UST duration for each maturity bucket relies on the duration from various Barclays indices back to 1976 and before that a simple time to maturity (in years) for each bucket. The lower panel shows a weekly decomposition of the balance sheet into its main asset components since December 2002. Data sources: Federal Reserve Bulletin and H.4.1 releases at www.federalreserve.gov. Datastream. 
Figure 4. Estimated factors in the baseline model.
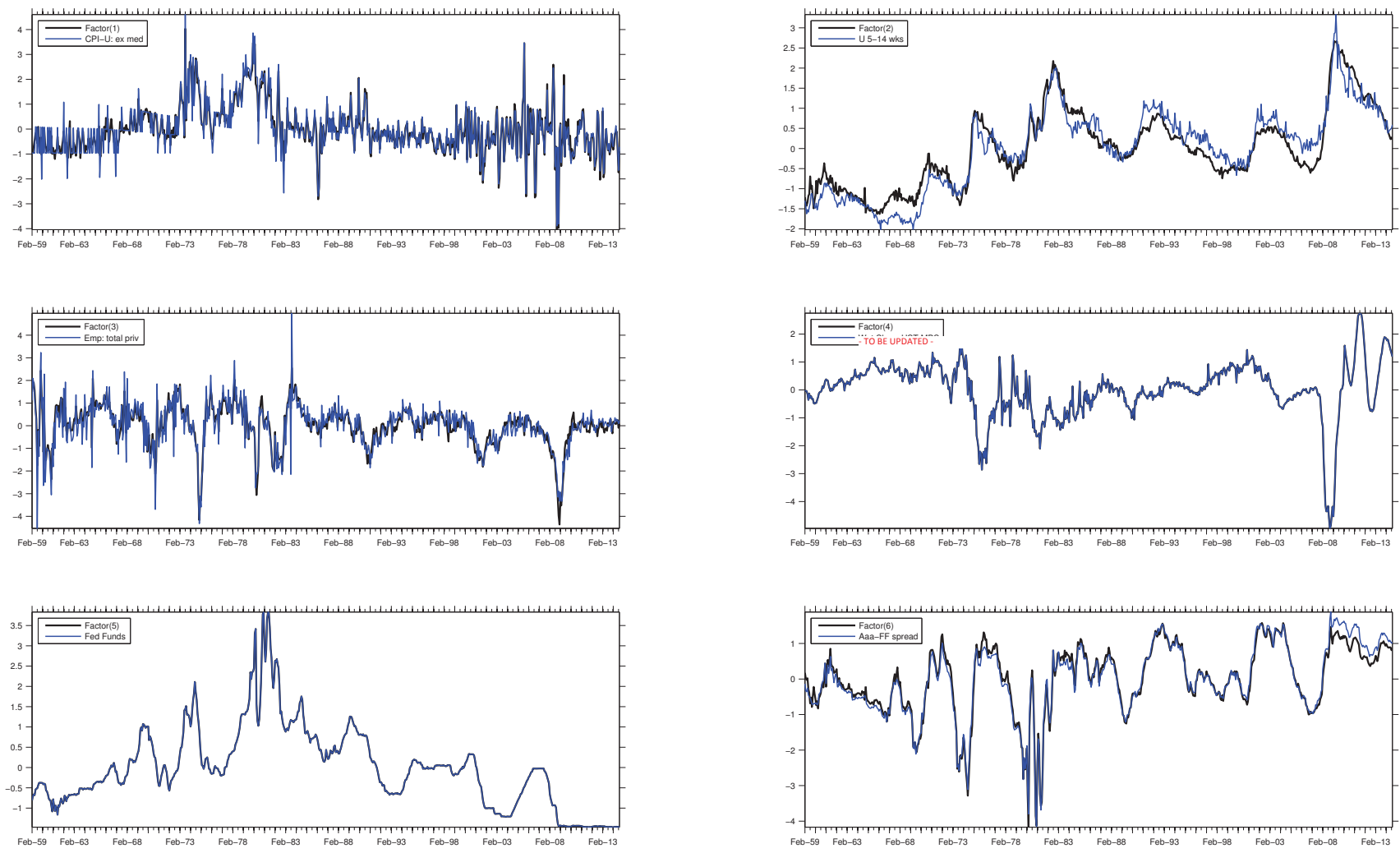

The figure illustrates the estimated factors from the baseline model. The legends show the observed variable in the panel with which the factor is most correlated with. CPI-U ex. med is consumer price inflation excluding the medicine component. U 5-14 is duration of unemployment. Emp. total priv is total private employment (in log differences). One of the sub plots needs to be updated with the relative risk share. This factor and the Fed Funds is perfectly measured. Aaa FF spread is the spread between the AAA corporate bond yield and the federal funds rate. 
Figure 5. Impulse responses to an unconventional monetary policy shock: Sign restrictions.
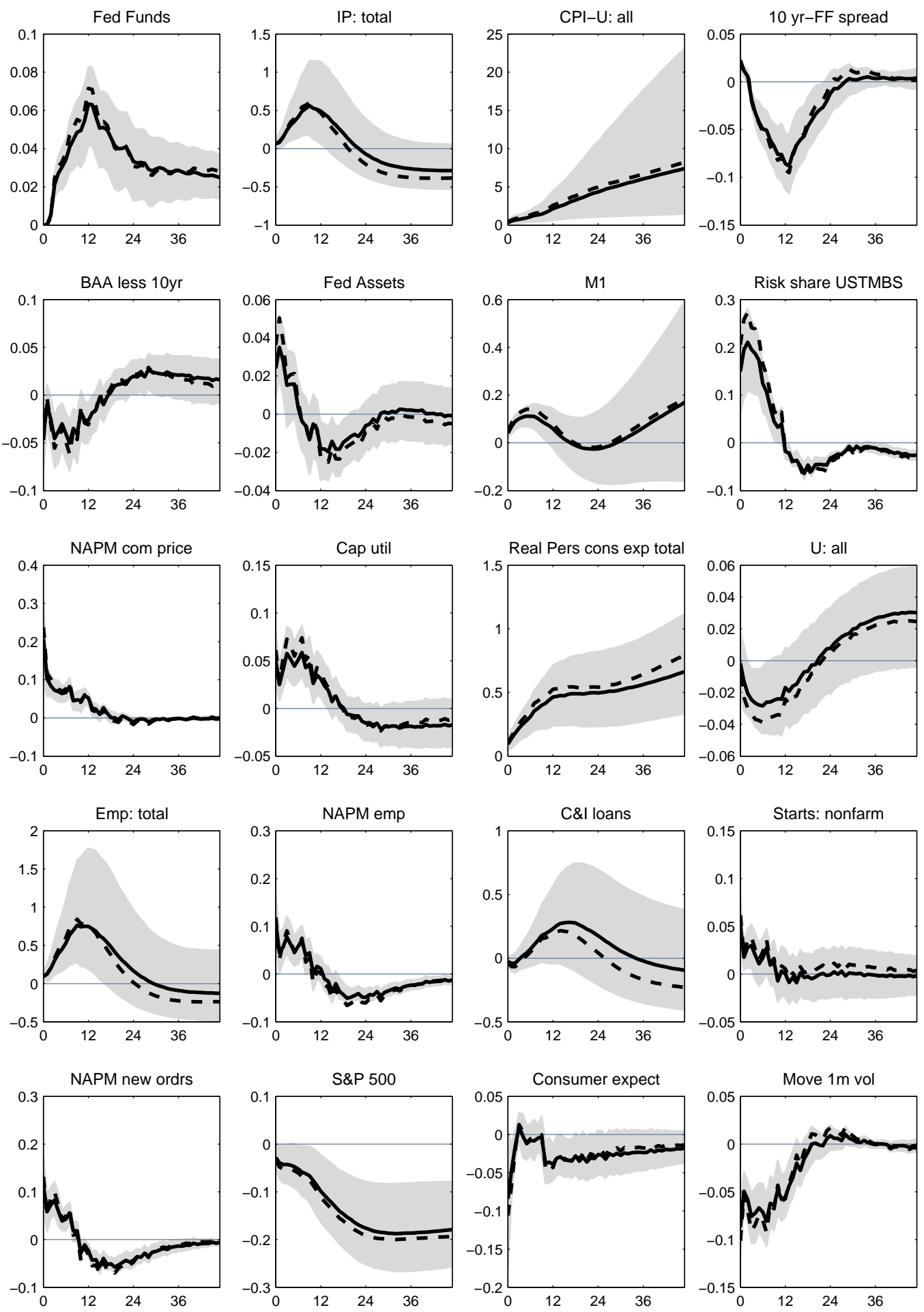

The figure illustrates the impulse responses of key macroeconomic variables to a positive shock to unconventional monetary policy identified by zero and sign restrictions. All responses are normalized by considering a one percent change in the innovations to the market share (Wgt Share). Vertical axes are measured in standard deviations. Horizontal axes show time horizon. The $68 \%$ confidence intervals are shaded and based on the first $10^{4}$ satisfied draws out of a total of $10^{6}$ generated draws. 
Figure 6. Impulse responses to an expansionary shadow rate shock: Cholesky.
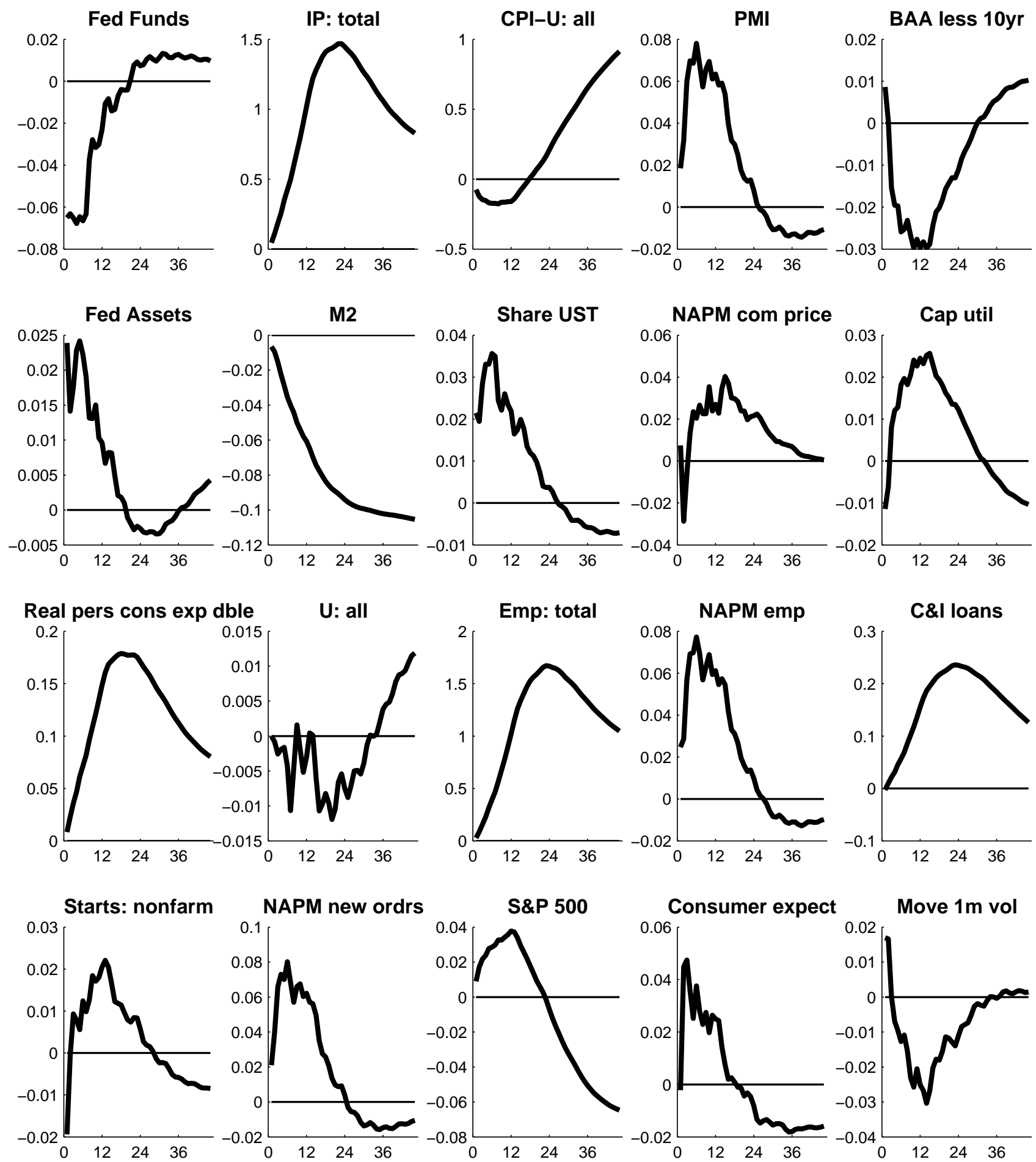

The figure illustrates the impulse responses of key macroeconomic variables to an expansionary shock to the shadow federal funds rate identified by the recursiveness assumption. The shadow rate is from Wu and Xia (2014). The policy shock is here chosen to be expansionary to be comparable to the unconventional shocks in this paper. In order to compare with the emprical literature on conventional monetary policy, in particular Bernanke et al. (2005), one would have to multiply the impulse responses by minus one. Vertical axes are measured in standard deviations. Horizontal axes show time horizon. 
Figure 7. Counterfactual analysis of a lower market share of UST and MBS.
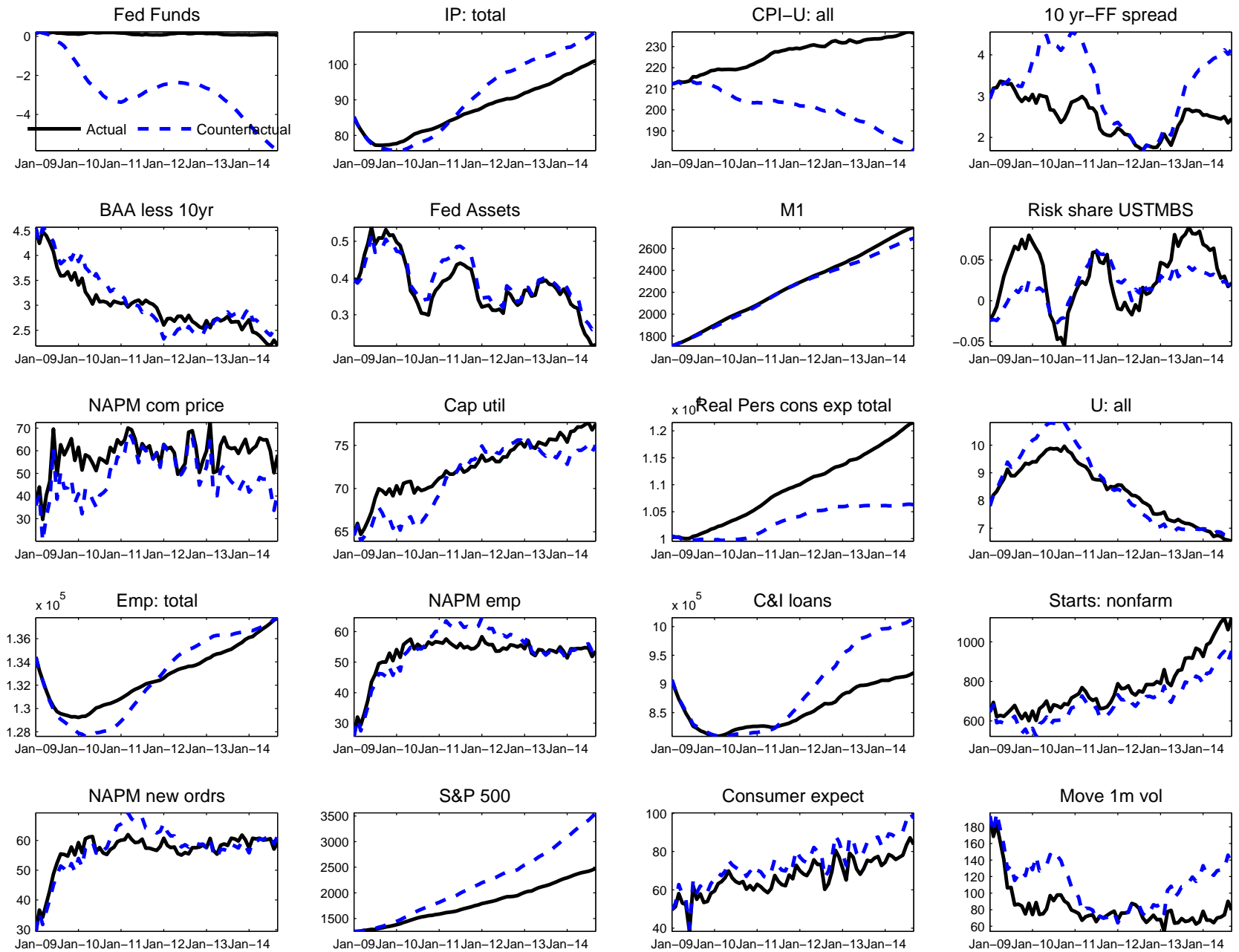

The figure illustrates the results of a counterfactual analysis of no MBS purchases by the Federal Reserve Bank. This implies a lower market share of UST and MBS which is the key to the counterfactual analysis. All the results are based on the closest-to-median model; the socalled Median Target model of Fry and Pagan (2011). 
C Supplementary material intended for online publication 
Figure B.1. Robustness analysis: Impulse responses to an unconventional monetary policy shock with 6 lags.
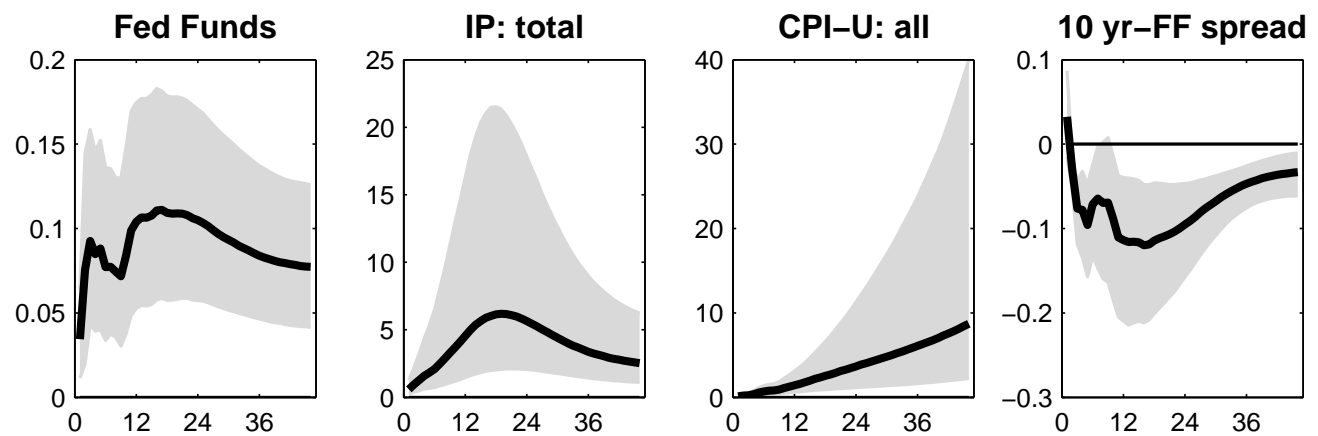

BAA less $10 \mathrm{yr}$
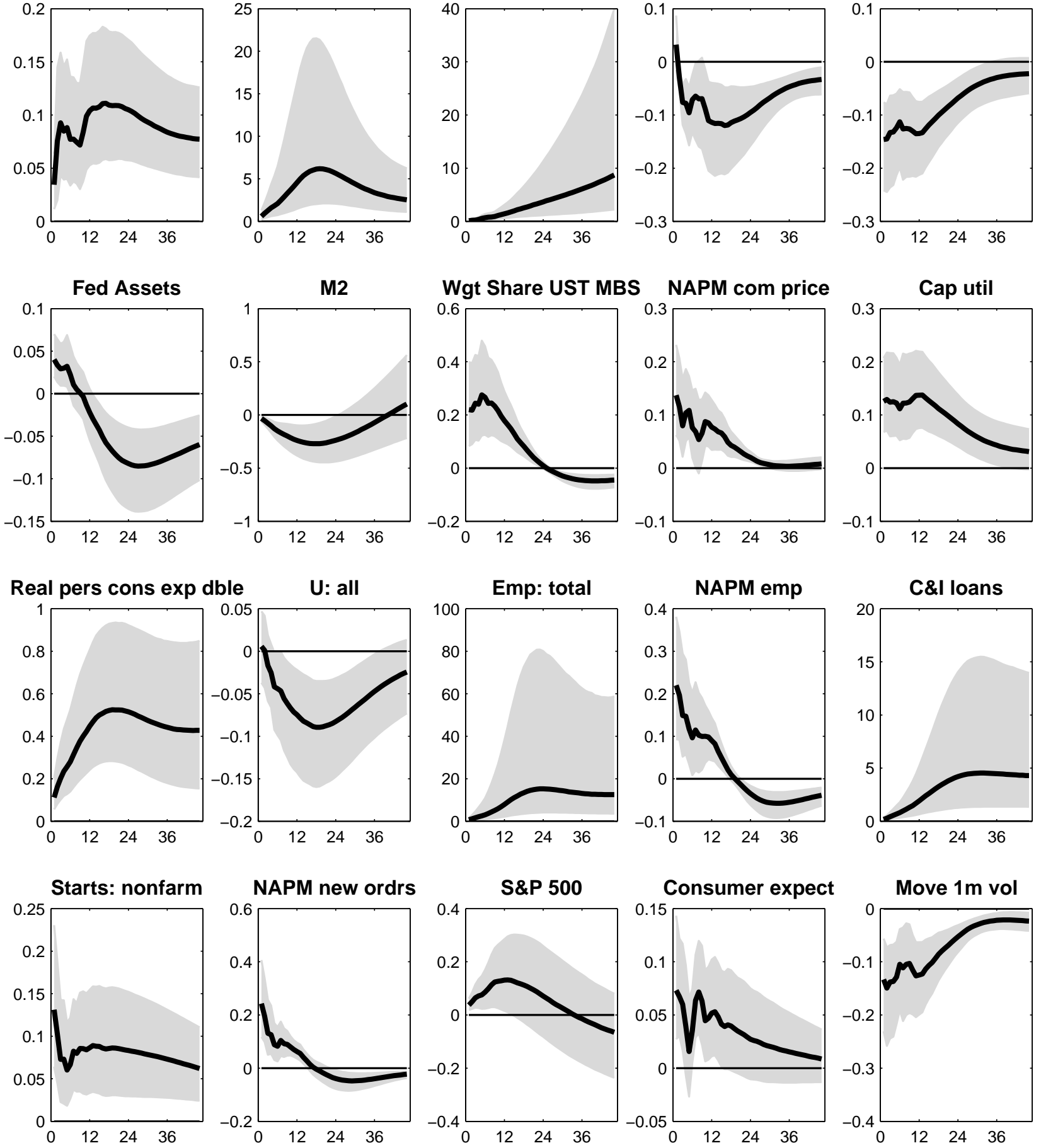

The figure illustrates the impulse responses of key macroeconomic variables to a positive shock to unconventional monetary policy identified by zero and sign restrictions. All responses are normalized by considering a one percent change in the innovations to the market share (Wgt Share). Vertical axes are measured in standard deviations. Horizontal axes show time horizon. The $68 \%$ confidence intervals are shaded and based on the first $10^{4}$ satisfied draws out of a total of $10^{6}$ generated draws. 
Figure B.2. Robustness analysis: Impulse responses to an unconventional monetary policy shock with 10 lags.
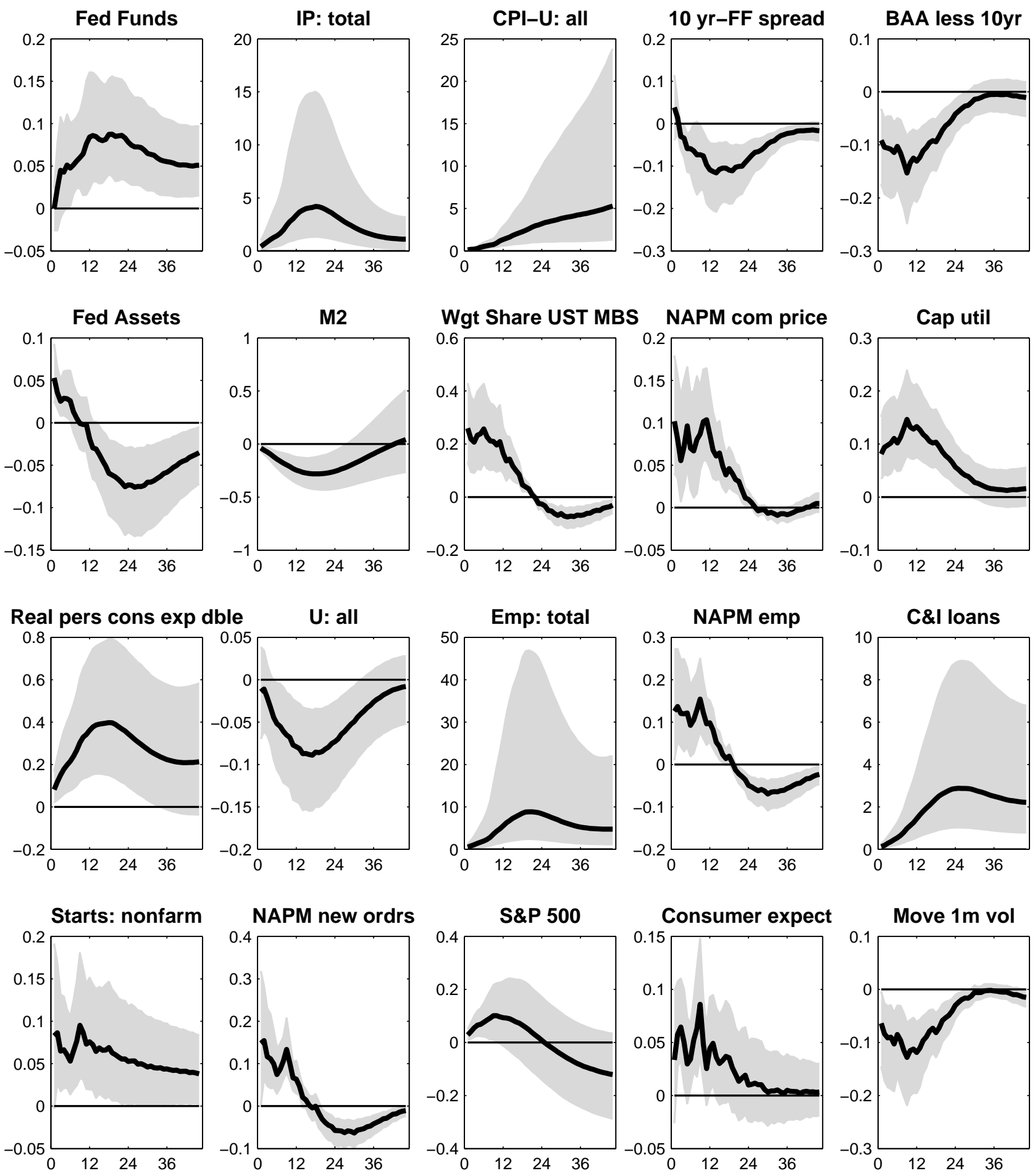

The figure illustrates the impulse responses of key macroeconomic variables to a positive shock to unconventional monetary policy identified by zero and sign restrictions. All responses are normalized by considering a one percent change in the innovations to the market share (Wgt Share). Vertical axes are measured in standard deviations. Horizontal axes show time horizon. The $68 \%$ confidence intervals are shaded and based on the first $10^{4}$ satisfied draws out of a total of $10^{6}$ generated draws. 
Figure B.3. Robustness analysis: Residual autocorrelation.
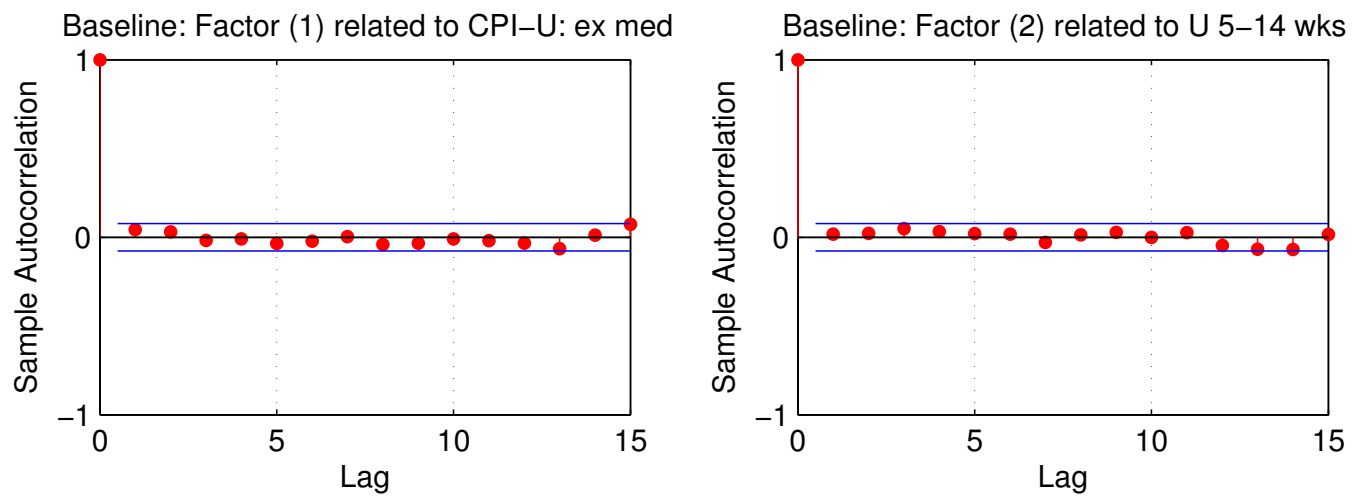

Baseline: Factor (3) related to Emp: total priv

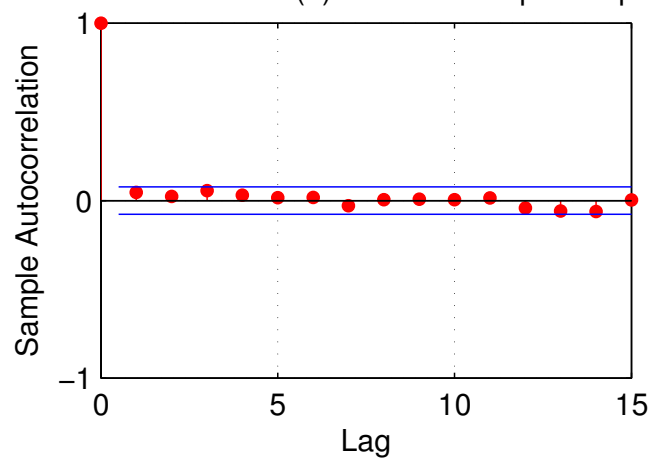

Baseline: Factor (4) related to Wgt Share UST MBS

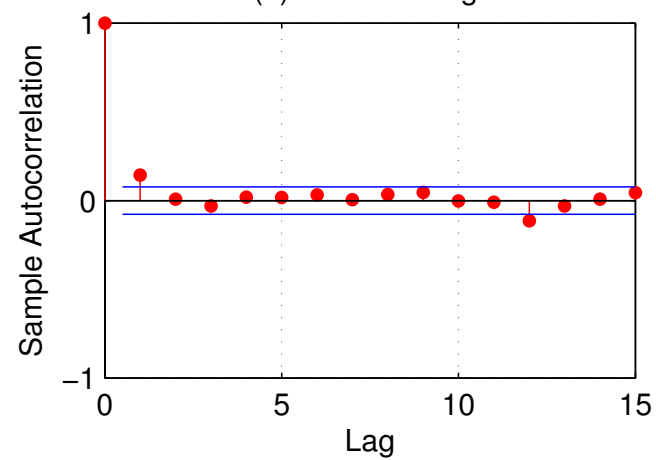

Baseline: Factor (5) related to Fed Funds

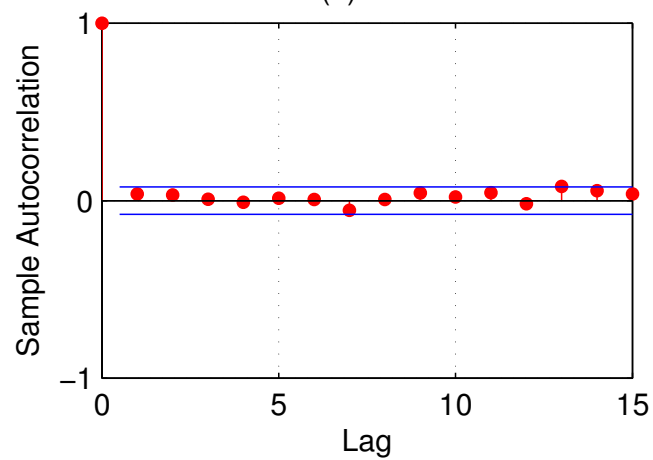

Baseline: Factor (6) related to $10 \mathrm{yr}-F F$ spread
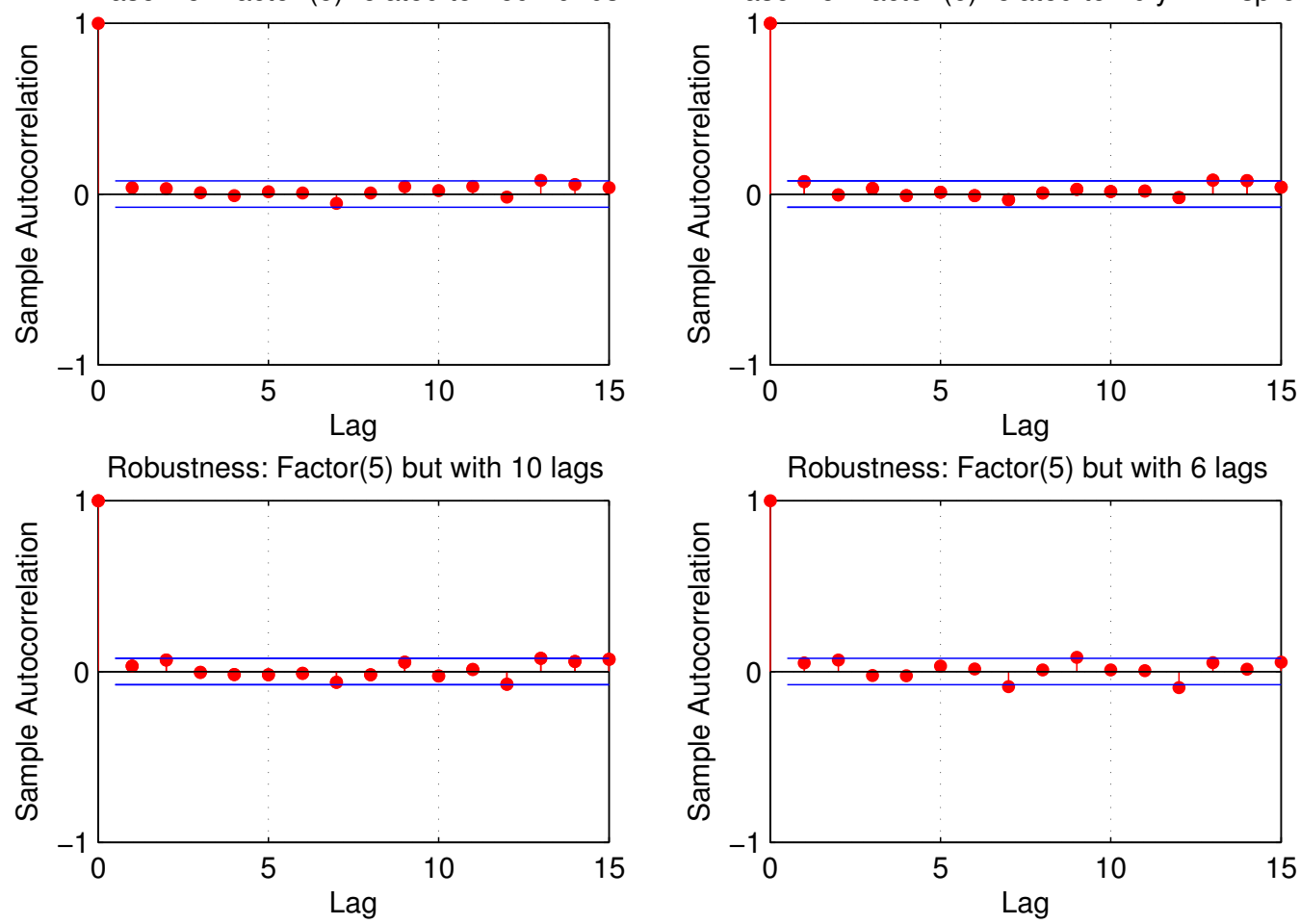

The figure plots the autocorrelation of the VAR residuals of the dynamic factor model. The upper six plots represent the baseline model for each of the six factors. As a robustness anlysis, the lower two plots show the residual autocorrelation for the monetary policy factor in an alternative model specification with $p=6$ and $p=10$ lags, respectively. 
Figure B.4. Robustness analysis: Impulse responses to an unconventional monetary policy shock during 1959-2007.
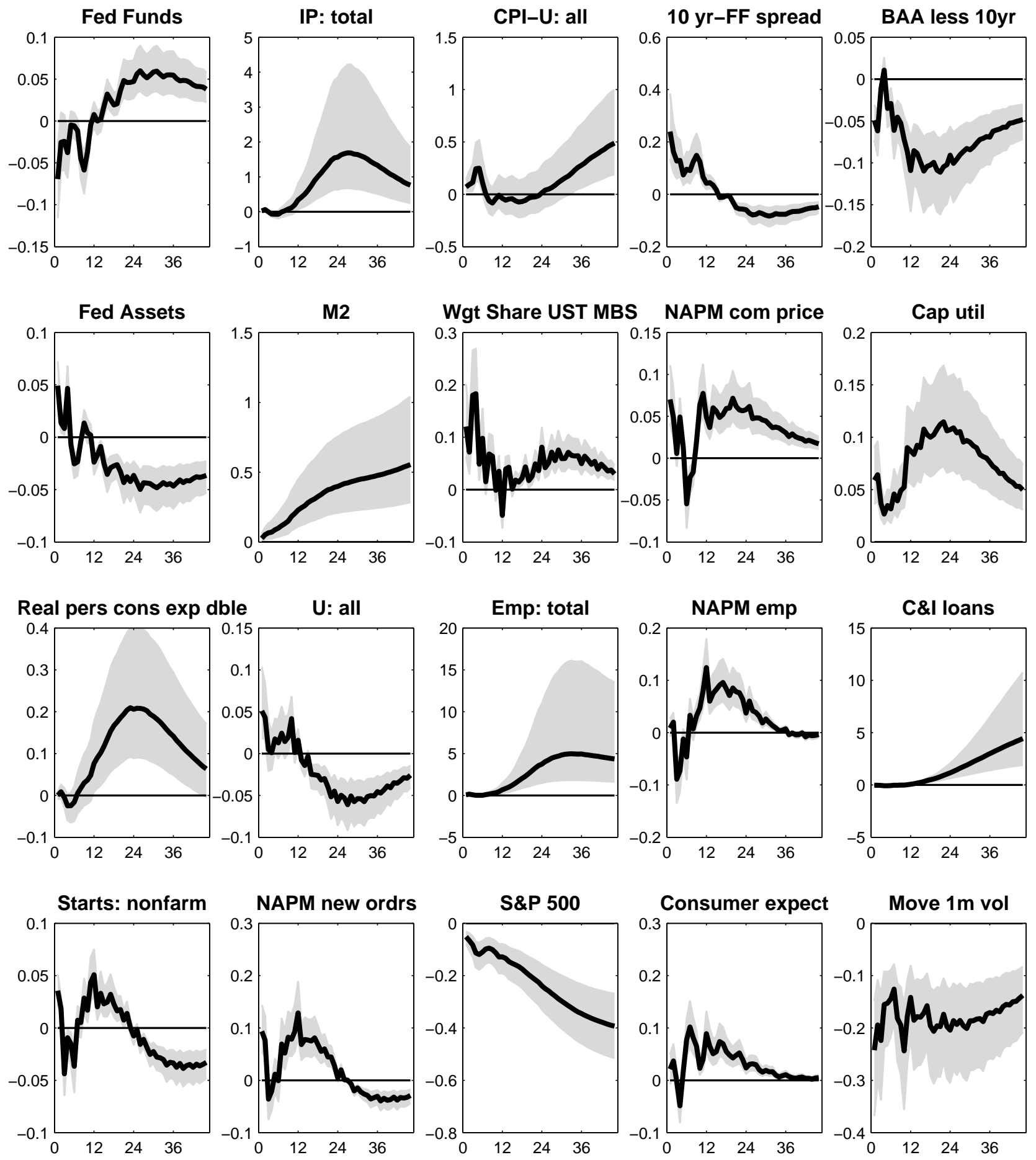

The figure illustrates the impulse responses of key macroeconomic variables to a positive shock to unconventional monetary policy identified by zero and sign restrictions. The sample is reduced to 1959-2007. All responses are normalized by considering a one percent change in the innovations to the market share (Wgt Share). Vertical axes are measured in standard deviations. Horizontal axes show time horizon. The $68 \%$ confidence intervals are shaded and based on the first $10^{4}$ satisfied draws out of a total of $10^{6}$ generated draws. 
Figure B.5. Robustness analysis: Impulse responses to an unconventional monetary policy shock using the non-weighted market share.
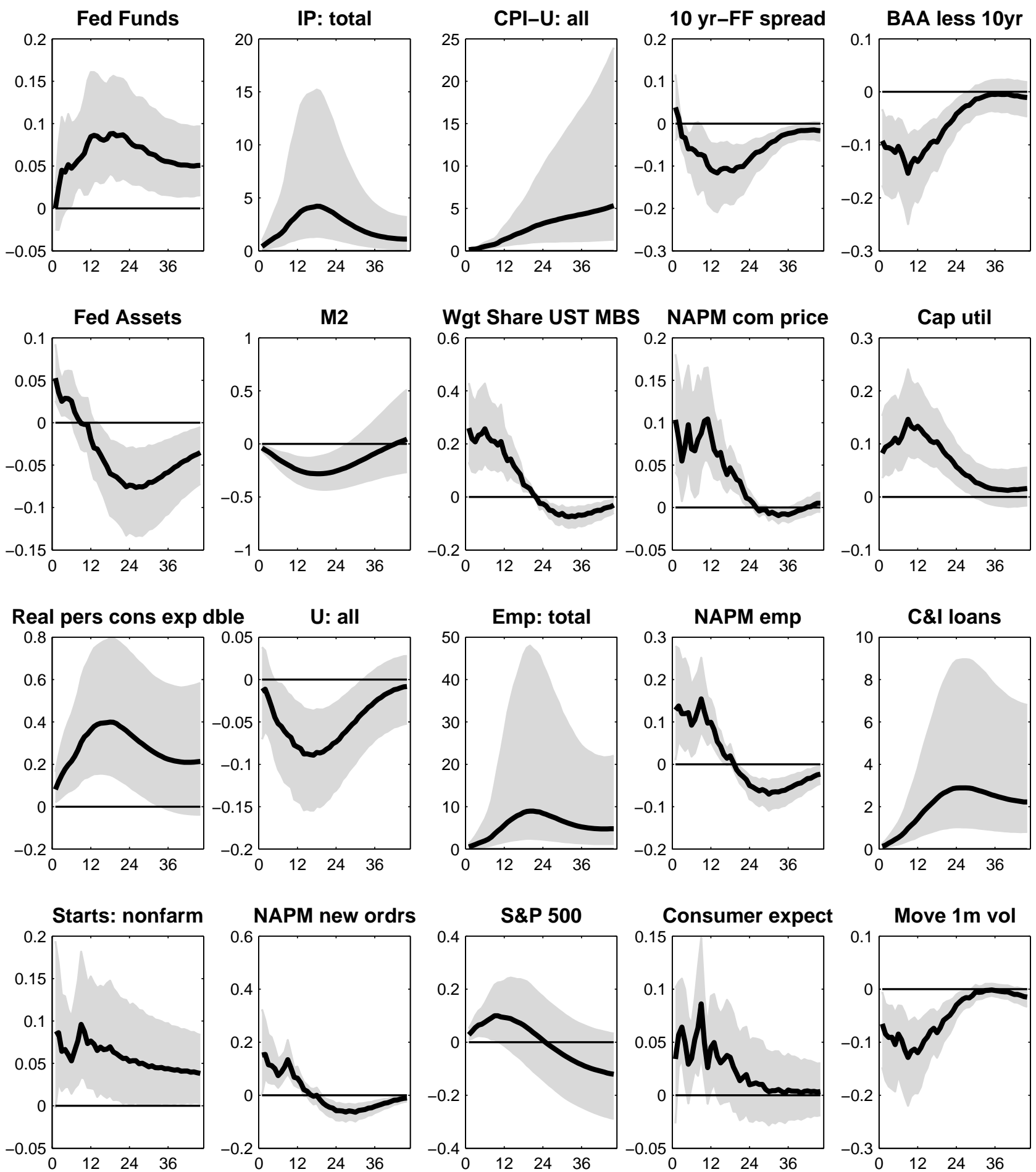

The figure illustrates the impulse responses of key macroeconomic variables to a positive shock to unconventional monetary policy identified by zero and sign restrictions. In this figure, the weighted market share is replaced by the non-weighted market share. All responses are normalized by considering a one percent change in the innovations to the market share. Vertical axes are measured in standard deviations. Horizontal axes show time horizon. The $68 \%$ confidence intervals are shaded and based on the first $10^{4}$ satisfied draws out of a total of $10^{6}$ generated draws. 
Figure B.6. Robustness analysis: Impulse responses to an unconventional monetary policy shock using the UST market share only.
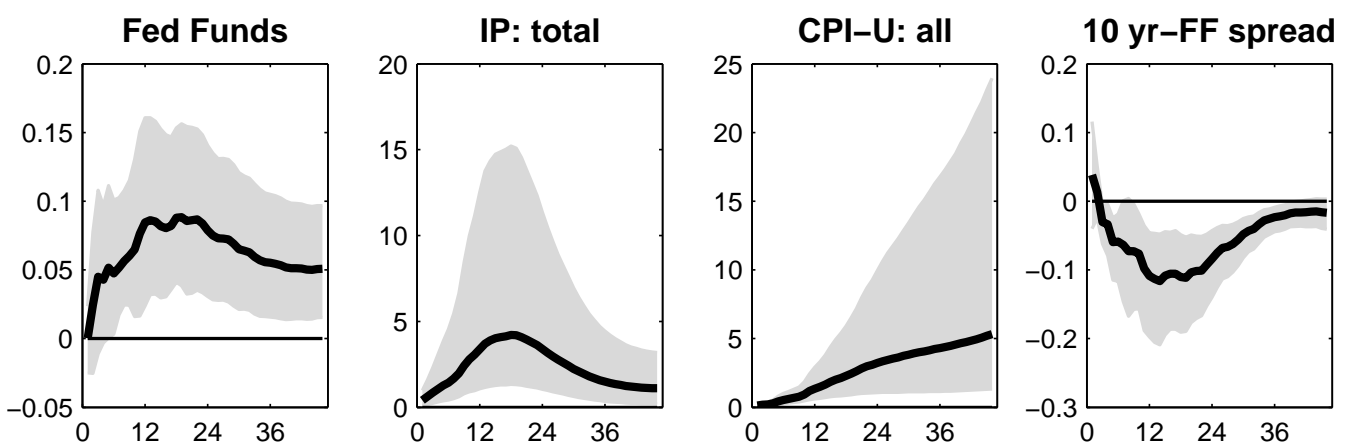

BAA less 10yr
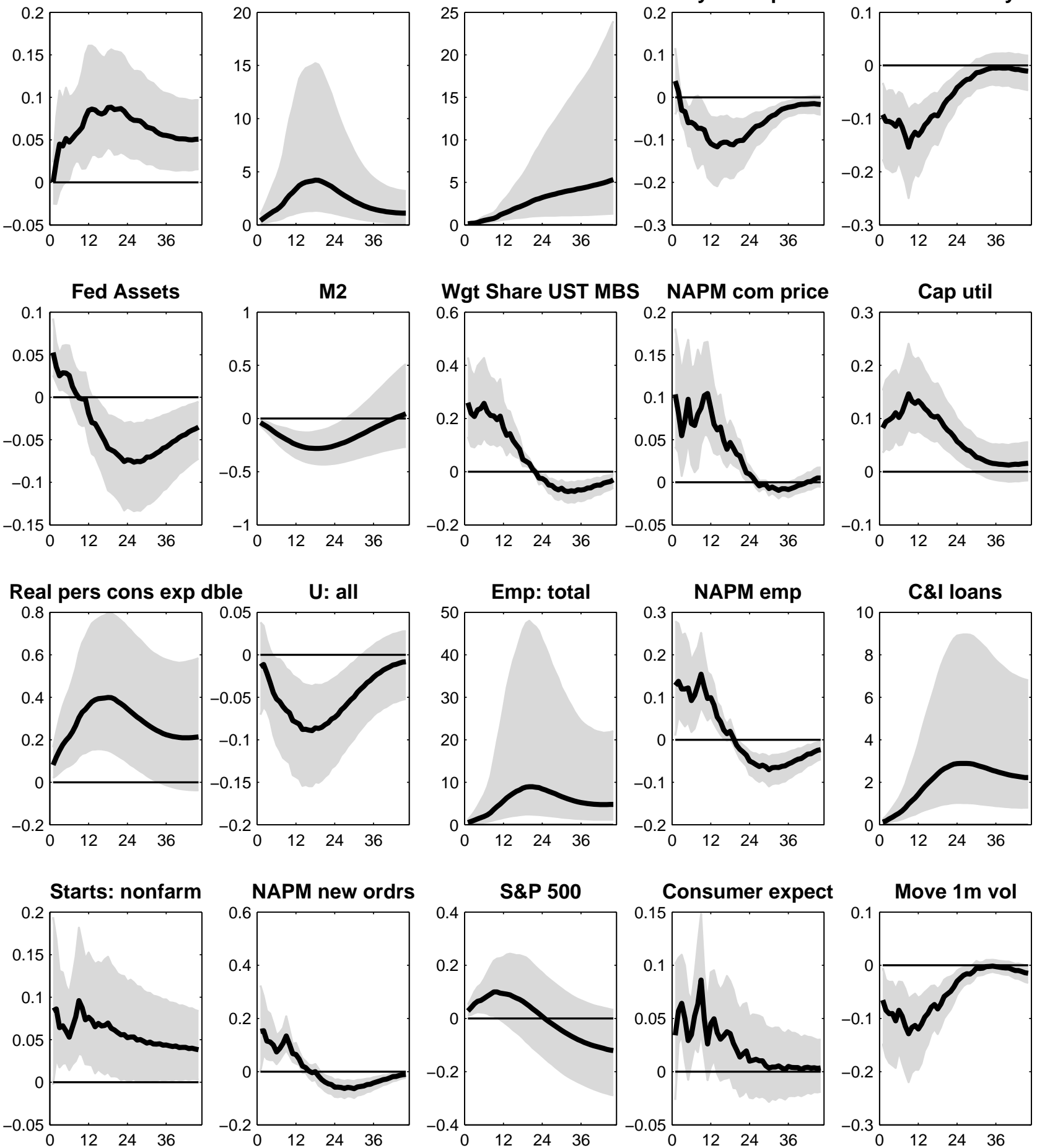

The figure illustrates the impulse responses of key macroeconomic variables to a positive shock to unconventional monetary policy identified by zero and sign restrictions. In this figure, the weighted market share is replaced by the non-weighted market share. All responses are normalized by considering a one percent change in the innovations to the market share. Vertical axes are measured in standard deviations. Horizontal axes show time horizon. The $68 \%$ confidence intervals are shaded and based on the first $10^{4}$ satisfied draws out of a total of $10^{6}$ generated draws. 